Portland State University

PDXScholar

1992

\title{
Multiple Code Switching in an Okinawan Speech Community: An Ethnographic Perspective
}

Izumi Kawamitsu

Portland State University

Follow this and additional works at: https://pdxscholar.library.pdx.edu/open_access_etds

Part of the Japanese Studies Commons

Let us know how access to this document benefits you.

\section{Recommended Citation}

Kawamitsu, Izumi, "Multiple Code Switching in an Okinawan Speech Community: An Ethnographic Perspective" (1992). Dissertations and Theses. Paper 4091.

https://doi.org/10.15760/etd.5980

This Thesis is brought to you for free and open access. It has been accepted for inclusion in Dissertations and Theses by an authorized administrator of PDXScholar. Please contact us if we can make this document more accessible: pdxscholar@pdx.edu. 
AN ABSTRACT OF THE THESIS OF Izumi Kawamitsu for the Master of Arts in Speech Communication presented May 27, 1992.

Title: Multiple Code Switching in an Okinawan Speech Community: An Ethnographic Perspective

APPROVED BY MEMBERS OF THE THESIS COMMITTEE:

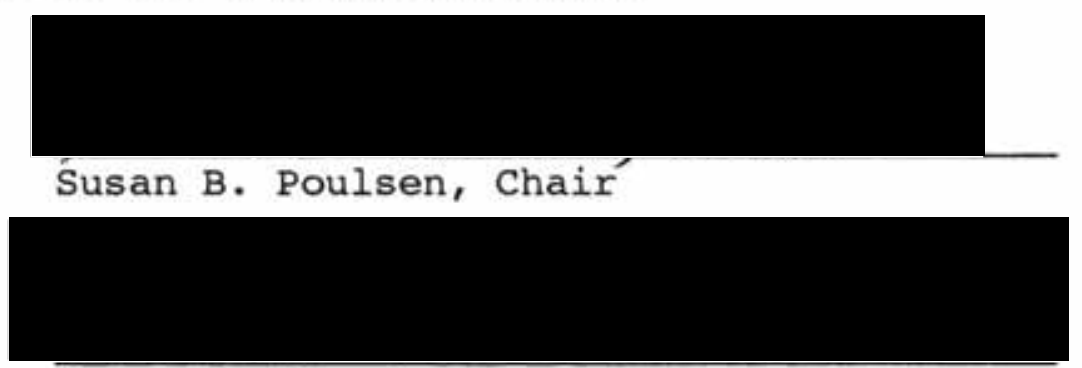

Peter C. Ehrenhaus

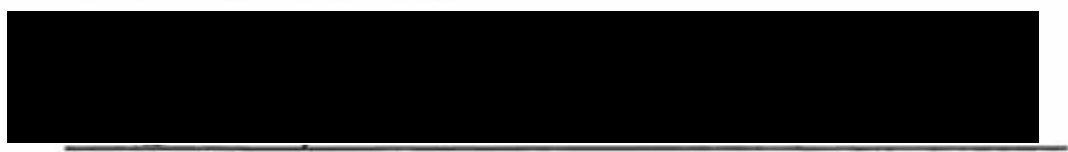

Suwako Watanabe

The ethnography of communication is a mode of inquiry which investigates relationships between language and culture in a particular speech community. Based on the ethnographic perspective, this study examines a certain way of speaking at a specific historical moment in a specific community. The major focus is two disc jockeys who are characterized as "trilingual" speakers (Japanese-English-Okinawa dialect) and their code switching activities in an Okinawan local radio 
program.

The three-month field study took place on the island of Okinawa. Data were collected from observations at the two radio stations, transcriptions of the program, and interviews with the DJs, the program director, program listeners, and older Okinawan residents.

The situational and metaphorical code switching patterns found in the DJs' verbal interactions include: obligational code choice, topic related code choice, interjections, quotations, translations, a lack of language proficiency, reiterations, and addressee specification. Using language which reflects "we" versus "they" orientation was a major determinant of the DJs' code choices. While the DJs use dialect to maintain okinawan group identification, the use of English appeared directed toward loosening the social separation between Okinawans and Americans who belong to mutually exclusive speech communities.

In addition to these functions of code switching related to the general social context in Okinawa, the study finds that the DJs and program listeners share the particular sociolinguistic values and therefore create a specific speech community. The DJ' use of three codes discloses two cultural phenomena in this young Okinawan speech community. One is the enhancement of Okinawan identity as a resistance to Japanization and the other is the acceptance of the American influence as part of local culture. 
Although the DJs are known to be "trilingual" among the younger people, the older generation defines the DJs' dialect as Okinawan-Japanese, which is a Creole produced language contact between the okinawa dialect and Japanese. In a strict grammatical analysis, most of the DJ' dialect is not spoken in pure form of the okinawa dialect. However, using dialect in a certain way, the DJs maintain and share Okinawan group identity with the young program fans. Simultaneously, the mixed-background English speaking radio hosts are also accepted by listeners as a symbol of new Okinawa where the American influence has become an indispensable factor in creating its unique characteristics. The success of the "trilingual" entertainers reveals the current situation in the young okinawan speech community where a cultural interrelation between mainland Japan, America, and Okinawa can be discovered. 
MULTIPLE CODE SWITCHING IN AN OKINAWAN

SPEECH COMMUNITY: AN ETHNOGRAPHIC PERSPECTIVE

by

IZUMI KAWAMITSU

A thesis submitted in partial fulfillment of the requirement for the degree of

\author{
MASTER OF ARTS \\ in \\ SPEECH COMMUNICATION
}

Portland State University

1992 
TO THE OFFICE OF GRADUATE STUDIES:

The members of the Committee approve the thesis of

Izumi Kawamitsu presented May 27, 1992.

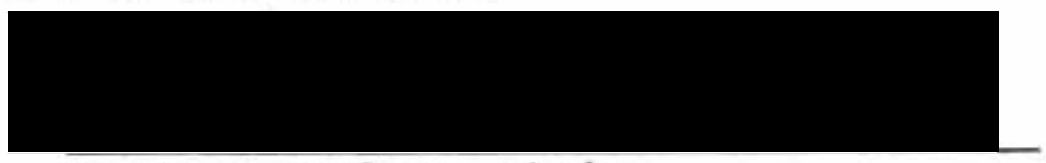

Susan B. Poulsen, Chair

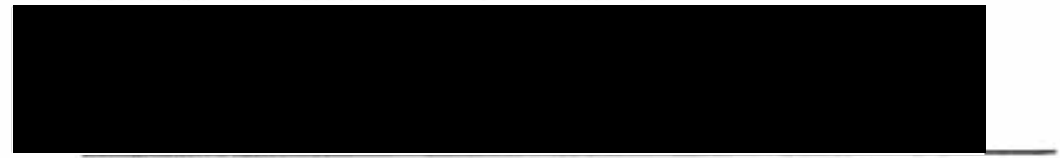

Peter C. Ehrenhaus

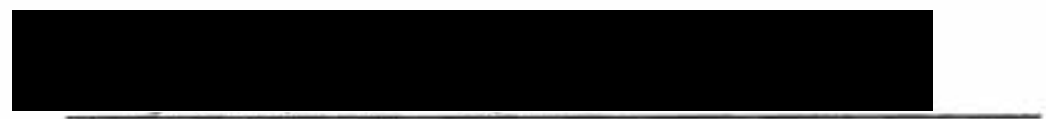

Suwako Watanabe

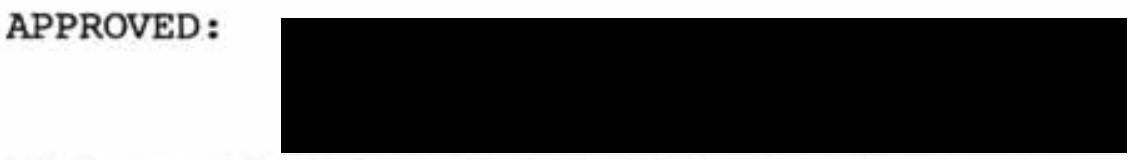

Theodore G. Grove, Chair, Department of Speech Communication

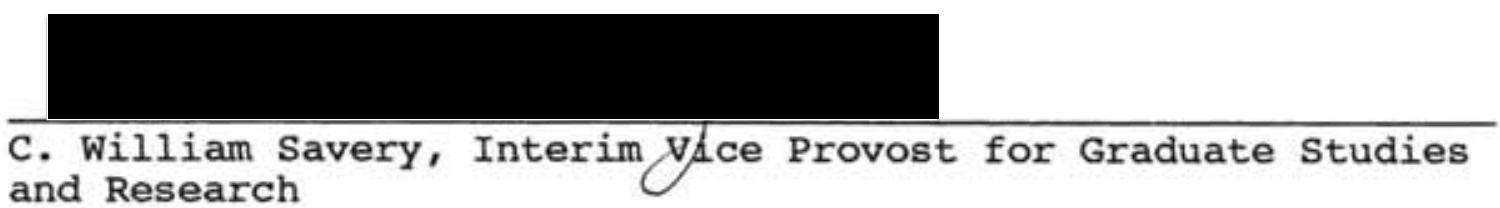


To Okinawans 


\section{ACKNOWLEDGMENTS}

At the last moment of writing a thesis as a first practice of becoming a thinker, I wish to express my gratitude to the members of my thesis committee. I am especially grateful to Dr. Susan Poulsen, chairperson of my committee, who introduced me in this inquiry of academe with direction and insight.

I am also indebted to my writing adviser, Robin Davison, for her writing assistance. Working with her Western linear mind was fun and valuable.

I thank Komina, my sister, whose understanding, support, and unending encouragement helped me to go through many difficult periods. Lastly, my sincere appreciation is extended to my parents who gave me determination and strength in pursuing education. Without their love, this study had never been accomplished. 
TABLE OF CONTENTS

PAGE

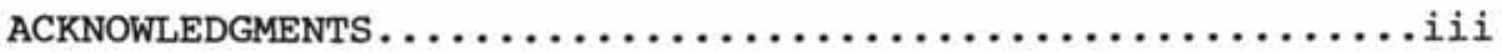

LIST OF FIGURES........................

CHAPTER

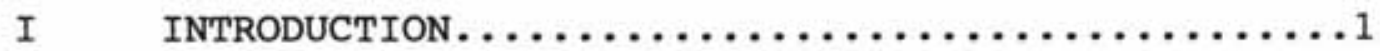

Research Purpose.................

Definition of Code..................

Significance of the Investigation.......4

The Research Questions............

Overview of the Study $\ldots \ldots \ldots \ldots \ldots \ldots \ldots$

II REVIEW OF THE LITERATURE $\ldots \ldots \ldots \ldots \ldots \ldots \ldots \ldots \ldots \ldots \ldots \ldots \ldots$

Code Switching: An Ethnographic

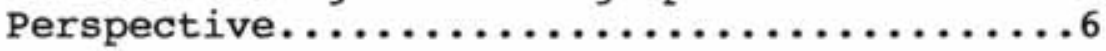

Introduction

The Ethnography of Communication: Theoretical Background

Code Varieties and Switching

Structures of Code Switching

Functions of Code Switching

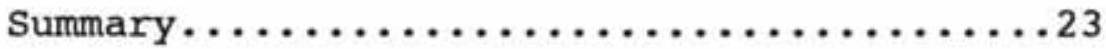

III HISTORICAL BACKGROUND OF THE RESEARCH FIELD $\ldots \ldots 24$

Okinawa....................... 24

Okinawan History

Languages in Okinawa.................. 29

Languages in Japan

Okinawan Dialects 
Japanese Language Planning in Okinawa Language Transition and its Consequences Summary of Languages in Okinawa

METHODOLOGY ....................

Qualitative Research Methods........40

The Ethnography of Communication.......42

Validity and Reliability ...........46

Validity

Reliability

Research Procedures............... 50

Data Collection Procedures

Sampling and Interviewing Procedures

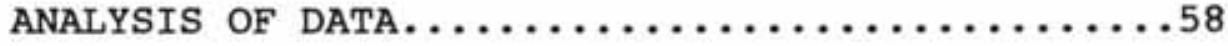

Interview Results..............58

Interviews with Listeners

Interviews with Older Locals

Interview with Ken and Masumi

Interview with the Director

Summary of Interview Results........69

Description of the Research field.......71

Speech Communities in Okinawa

The Research Field

Analysis of "Pop'n Roll Station"........78

Analysis of Mnemonic SPEAKING:

Pop'n Roll Station

Analysis of Code Switching...........86

Structures and Functions of the Code Switching

Situational Code Switching

English Situational Code Switching

Japanese Situational Code Switching

General Sociolinguistic Norms in the

Okinawan Speech Community

Metaphorical Code Switching 
Dialect Metaphorical Code Switching: Dialect as the "We" Code English Metaphorical Code Switching: English as the "We" Code

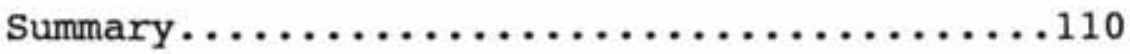

VI ARGUMENTATION AND CONCLUSION............. 112

Review of the Research Findings.......112

Function of Boundary-Maintenance.......116

Dialect as Okinawan Group Identity

Okinawan Cultural Revival and the Young Okinawans

Social Identity and Dialect

Future of Dialect and Identity

Function of Boundary-Leveling.........122

DJs as Brokers between Okinawans and Americans

Accepting American Influence as Part of Okinawa

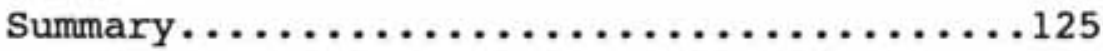

Study Limitations and Contributions.....126

Implications for Future Research.......129

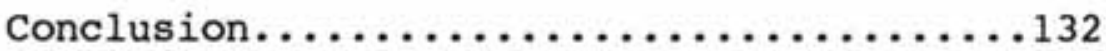

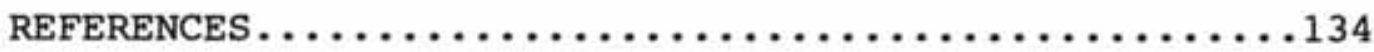

APPENDICES

A INFORMED CONSENT ............... 141

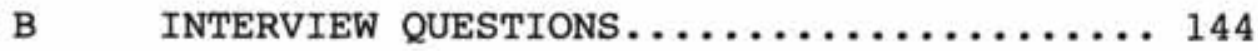

C TRANSCRIPTION CONVENTIONS......... 147 


\section{LIST OF FIGURES}

FIGURE

PAGE

1 The Relationship between Japanese and

Okinawan Dialects.....................

2 The Language Transition Process............. 33

3 Structure of Pop'n Roll station............77 
CHAPTER I

INTRODUCTION

The function of language is of concern to various disciplines. By applying inductive analysis of culturally patterned and organized communication in societies or communities, scholars from different perspectives have tried to build upon the understanding of how linguistic knowledge and social factors interact within discourse (Gumperz, 1982; Hymes, 1986; Heller, 1988). As one type of research which is subsumed under qualitative or naturalistic inquiry, the ethnography of communication focuses on the relationship between social structure and language use. Based on the ethnographic perspective, this study examines a particular way of speaking at a specific historical moment in a specific community. The major focus is two disc jockeys (DJs) who are generally characterized as "trilingual" speakers (JapaneseEnglish-okinawa dialect) by natives and their multiple code switching activities in an Okinawan local radio program.

\section{RESEARCH PURPOSE}

Okinawa is a separated Japanese prefecture, a regional district administered by a governor, which is located in the south end of Japan. Due to its historical experiences of 
being conquered by Japan in the seventeenth century and controlled by American military after World War II, Okinawa has developed differently from mainland Japan.

In the present social situation framed by the historical developments, a new way of speaking consisting of Japanese, English, and the Okinawa dialect has emerged on a local radio program entitled "Pop'n Roll Station" hosted by two Okinawanborn-Japanese-American disc jockeys, Ken Rabillard and Masumi Rodriguez. [Note: Okinawans are technically Japanese. Since there is not a term like Okinawan-Japanese in the Japanese language, this expression is considered to be the most appropriate.] Recently, their way of speaking has gained listeners' attention and their program has become popular. One of the local writers of Okinawa Keyword Column Book (Shinjo, 1988) describes the program as follows:

Pop'n Roll Station: It is a popular radio program of FM Okinawa for younger people. It is on the air from 7 p.m. to 9 p.m.....this program hired racially mixed people as DJs and became a representative of the new Okinawan radio program by introducing a way of speaking which is a mixture of Japanese, dialect and English.... I would say, especially Ken \& Masumi are great. Since they speak in that way, their conversation might sound confusing for the first time. Old people might think "What are they saying?" But once you get used to it, you will notice their conscious emphasis upon "uchinaa" (Okinawa).... Okinawan teenagers are exposed to this "Okinawaness" that they can find in their everyday life (p. 183).

I have been interested in why this "trilingual" phenomenon is happening and what the reasons are for these disc jockeys' popularity. What are they saying in their 
conversations in the program? When do they code switch? How do listeners feel about their way of speaking? How do listeners' responses influence these disc jockeys' speaking? Why do people, especially young people, accept this way of speaking? Why has this way of speaking emerged at this time in Okinawan society?

The purpose of this study is to examine the disc jockeys' code switching activities which take place during their show, "Pop'n Roll Station," in order to discover the socially situated meaning of the language use in this particular speech community at this point in time. I will investigate code switching features, patterns, and its social significance in light of the historical development of Okinawa as a Japanese prefecture together with the residual effects of World War II, that is, the continual presence of the U.S. military bases. I will identify and analyze the dynamic interrelationship among elements which go to make up this social phenomenon.

\section{DEFINITION OF CODE}

Code is an important term in this study. It refers to language or an internal variation of a language such as standard language, regional dialect, social dialect, Pidgin, Creole, style, and register (Wardhaugh, 1990). Study of code therefore exhibits a great range of focus from language to those varieties within a language. Since my study of code 
switching concerns two different levels, language and dialect, I define Japanese, English, and "the Okinawa dialect," which is a dialect spoken on the island of okinawa, as the codes to be investigated. Style and register within these codes are considered important features which signal code choices but not the code itself.

\section{SIGNIFICANCE OF THE INVESTIGATION}

Study of code switching in Japan has been conducted primarily in the linguistic analysis of Japanese-English bilingualism by examining the grammatical structure of language (Nishimura, 1986; Nishimura, 1989; Higa, 1974; Kurokawa, 1974). There are limited language studies utilizing an ethnography of communication perspective (Loveday, 1986; Sanches, 1975). Similarly, the social meaning of language use in the Okinawa prefecture has not been extensively studied. Due in part to its great difference from Japanese, the focal point of language studies in Okinawa has been on linguistic features of dialect (Uemura, 1972; Hokama, 1977; Hattori, 1976; Yabiku, 1973).

By investigating a certain way of speaking in Okinawan society this study introduces an ethnographic perspective of language function which linguistic studies have overlooked. As the first study dealing with the trilingual code switching phenomenon which has recently emerged in Okinawan society, my investigation also contributes to an understanding of 
relationships between trilingual code switching and the social context within which it occurs. Finally, within the ethnographic tradition, this study will expand a line of ethnographic inquiry concerned with the social meaning of code switching (Blom \& Gumperz, 1986; Gumperz, 1982; Gumperz \& Cook-Gumperz, 1982; Saville-Troike, 1989).

\section{THE RESEARCH QUESTIONS}

1. What are the distinguishing features and functions of this code switching?

2. What is the interrelationship between this sociocultural context and the code switching as a particular way of speaking?

3. What is the meaning of code switching from the native speakers' point of view?

\section{OVERVIEW OF THE STUDY}

Chapter I has introduced the purpose of the study and its significance. Chapter II presents the literature review of code switching in order to provide theoretical background of the investigation. Chapter III provides historical information and the language situation in okinawa. Methodology is explained in chapter IV including the framework of the study as well as research procedures. Chapter $\mathrm{V}$ analyzes interview results and the DJs' code switching activities. Finally, chapter VI discusses the 
research findings, study limitations and contributions, implications for future research, and the research conclusion. 


\section{CHAPTER II}

\section{REVIEW OF THE LITERATURE}

This chapter discusses the concepts of the ethnography of communication and code switching.

\section{CODE SWITCHING: AN ETHNOGRAPHIC PERSPECTIVE}

\section{Introduction}

Code switching is the use of two or more languages or varieties of a language within a single communicative event (Scotten \& Ury, 1977). A recent estimate shows that about half of the world population speaks at least two languages (Aure, 1984), making code switching a widely observed phenomenon in bilingual, multilingual, and interethnic societies. Increased interest has encouraged scholars to establish two important approaches which provide new and insightful perspectives into code switching. The first pertains to the linguistic concerns in identifying syntactic constraints of code switching; the other is a sociallyoriented focus on motivations for, or functions of, code switching (Woolard, 1988). Code switching studies situated in the ethnography of communication perspective take the second approach in order to explore interactive events as a unit of analysis while the first examines sentences for the 
purpose of discovering grammatical features of language choice. Since this is an ethnographic study, a detailed discussion of specific linguistic components of code switching is not included in this chapter. Literature review introduces theoretical concepts of the ethnography of communication and the findings of code switching derived from previous studies based on the ethnographic perspective.

The Ethnography of Communication: Theoretical Background

The ethnography of communication is a form of naturalistic inquiry whose purpose is to describe and analyze the interaction between language and culture (Saville-Troike, 1989). First proposed by Dell Hymes as the ethnography of speaking in 1962, this field of inquiry has attracted the attention of scholars in a variety of disciplines who are concerned with language function in social settings. Later, the general terminology, the ethnography of communication, came to include the ethnography of speaking, since speaking is part of communication as a whole. According to Bauman and Sherzer (1975), the fundamental premise of this inquiry is that:

speaking, like other systems of cultural behaviors--kinship, politics, economics, religion, or any other--is patterned within each society in culture-specific, cross-culturally variable ways (p. 98).

The primary task of scholars in this field is to discover, describe, and analyze those patterns governing 
speaking in a specific community.

The ethnography of communication is designed to create "descriptive theories of speaking as a cultural system or as part of cultural systems" (Bauman \& Sherzer, 1975, p. 98). Ethnographers formulate such theories heuristically in the process of their investigations of particular speech communities (Blom \& Gumperz, 1986; Philipsen, 1977). Hymes (1986) states:

An adequate descriptive theory would provide for the analysis of individual communities by specifying technical concepts required for such analysis, and by characterizing the forms that analysis should take (p. 53).

One of the important focuses of the ethnography of communication is the speech community where a certain way of communication is patterned and organized (Saville-Troike, 1989). The generally given characteristics of a speech community include: a high frequency of interaction among members of a group (Gumperz, 1962), shared rules of speaking and interpretation of speech (Hymes, 1986), shared attitudes as well as value in language in use (Labov, 1986), and shared sociocultural understanding and presuppositions with regard to speech (Sherzer, 1975).

Yet scholars often find that the difficulty in defining a speech community is attributed to the fact that a community is not coterminous with a language (Saville-Troike, 1986; Wardhaugh, 1990). For example, the English language is spoken in various areas of the world. Although people in 
these areas share the same language, "it is also spoken in a wide variety of ways, in speech communities that are almost entirely isolated from one another" (Wardhaugh, 1990, p. 114). A question arises. How these communities are significantly different? An answer obviously cannot be given by linguistic features alone. To understand this phenomenon, one must know the history, culture, politics, and group identification that create the social nature of language in each area (Saville-Troike, 1986).

Wardhaugh (1990) also explains speech community as follows:

A community or group will be any set of individuals united for a common end, that end being quite distinct from ends pursued by other groups. Consequently, a person may belong at any time to many different groups or communities depending on the particular ends in view (p. 121).

Consequently, in bilingual societies, a person may shift his or her identification from one community to another, using one language on official occasions, for example, at work, but the other during private times at home. The concept of speech community is a flexible one since people bond themselves together for various purposes such as family, friendship, work, religion, and politics; therefore, there is no limit to the number of the speech communities that may coexist simultaneously within a single society (Bolinger, 1975). These communities may be discrete or overlapping. Wardhaugh (1990) argues that a consequence of such intersecting identification is linguistic variation, which 
reflects people's need to be part of a certain group on some occasions and be part of a different group on others. Saville-Troike (1989) discusses the necessity of recognizing that each speakers' identity in a given context is associated with appropriate verbal and nonverbal forms of expression. According to Hymes (1974), to participate in a speech community is not the same as to be a member of it:

Here we encounter the limitation of any conception of speech community in terms of knowledge alone even knowledge of patterns of speaking as well as of grammar, and of course, of any definition in terms of interaction alone. Just the matter of accent may erect a barrier between participation and membership in one case, although be ignored in another. Obviously membership in a community depends upon criteria which in the given case may not even saliently involve language and speaking, as when birthright is considered indelible (p. 50-51).

To speak in the same language allows a speaker a certain degree of participation, but membership cannot be obtained based on knowledge and skills alone, because it depends upon shared knowledge of rules for the conduct and interpretation of speech covertly embedded in a community (Saville-Troike, 1989; Williams, 1992).

In order to be part of a speech community, one must learn to be communicatively competent (Hymes, 1974). Communicative competence is another important notion of the ethnography of communication. Ethnographers' concern is with the issues of communicative competence as opposed to linguistic competence established by Noam Chomsky (1965). Hymes (1972) rejects the Chomskian concept of linguistic 
competence which accounts for speakers' ability to generate and understand sentences in terms of their knowledge of grammar, claiming, instead, that successful communication rests on the speakers' knowledge of their own culture and society. Gumperz (1982) also argues that linguistic competence derived from Chomskian generative grammar cannot account for the specifics of message interpretation, because the generative grammar assumes uniform linguistic rule systems and deals with cognitive process at a level of abstraction only. He maintains that "the ability to use linguistic variables, or prosodic or formulaic options, must form an integral part of a speakers' communicative competence" (p. 206). Saville-Troike (1989) explains this concept :

Communicative competence involves knowing not only language code, but also what to say to whom, and how to say it appropriately in any given situation. It deals with the social and cultural knowledge speakers are presumed to have to enable them to use and interpret linguistic forms (p. 22).

She points out that how speakers define and constrain interpersonal interactions is central to the communication strategies and essential to understanding a common mode of communication which exists in a community.

The notions of speech community and communicative competence are deeply interrelated; communicative competence cannot be understood, evaluated, and recognized without the speech community (Williams, 1992). Hymes (1974) emphasizes that language is a social phenomenon produced by 
interactions. Not only is a speech community a normative construct, having the shared knowledge of rules of speaking, it is also a social organization, involving shared goal orientations and role-relationships among its members (Saville-Troike, 1989). During these interactions, members learn appropriate and effective communication strategies (Hymes, 1974).

It is not necessary for a speech community to have only one linguistic criterion. The presence of a variety of codes within a community has been a major interest of the ethnography of communication (Saville-Troike, 1986). Bauman and Sherzer (1975) state that the study of code switching is most appropriately oriented towards discovering the "factors of the social meaning and values carried by the respective codes" (p. 105). Gumperz (1972) states that a variety of codes include "dialects or styles used in a particular socially defined population, and the constraints which govern the choice among them" (p. 217). Speakers select a code which is appropriate to the context. The ethnography of communication examines code switching phenomena in this relationship with culture and codes spoken in a specific community.

\section{Code Varieties and Switching}

Speakers' motivations for choosing a certain code is a major interest of scholars who take an ethnographic 
perspective in formulating descriptive theories of the social meaning of language. Although considered primarily a subconscious activity (Gumperz, 1982; Saville-Troike, 1989), code switching is nonetheless a meaningful communicative behavior and is governed by social norms and cultural values. Since choosing a code is a delicate matter, accounting for the code switching phenomenon is by no means a easy task. A great deal of effort has been made to discover determinants of certain code choices under specific conditions on specific occasions.

Ferguson (1959) examined societies where two distinct languages showed clear functional separation. He called this case diglossia. His studies investigated the use of classic and colloquial Arabic, Standard German and Swiss German, Haitian Standard French and Creole, and two varieties of Greek. He identified the following relationships between two codes in these diglossic societies: prestige, stability, literary heritage, acquisition, standardization, grammar, lexicon, and phonology. One code is defined as a high (H) variety of language and is given high prestige while the other is a low (L) variety of language and refers to various colloquial forms. Diglossia is commonly an extremely stable phenomenon and lasts for centuries. A literary heritage is in $\mathrm{H}$, but not in $\mathrm{L}$. Children learn $\mathrm{H}$ in school and $\mathrm{L}$ at home. The $\mathrm{H}$ variety is standardized with grammars, dictionaries, and standardized texts while the L variety 
lacks them. The grammar of $\mathrm{H}$ is more complex than that of $\mathrm{L}$. Although both varieties share vocabularies, there are complementary distribution of terms and distinctly different pairing of words. The sound system of $\mathrm{H}$ and $\mathrm{L}$ constitute a single phonological structure. Fasold (1984) stated that speaking High languages is also associated with speakers' values and the status of the wider community; speaking Low language demonstrates the cultural patterns of the smaller community.

Whereas diglossia shows a clear-cut distinction between the use of two codes in a whole society, there are societies which demonstrate different and complicated patterns of two or more codes. Language situations in these cases often involve nationalism, colonization, federation, migration, border areas, and ethnic groups (Fasold, 1984). Studies done in Paraguay, where Spanish and one American indigenous language are spoken, offers an example of multilingual politics.

Because of its long isolation from Spain and lack of Spanish-speaking population, the Spanish colonists started adopting one of the American indigenous languages, Guarani. As a consequence, Guarani has became a national language, spoken by 90 percent of the population while Spanish is a formal, official language used in government business and educational settings (Rubin, 1968). Rona (1966) reported that most of the people in cities are bilingual whereas the 
monolingual Guarani-speaking population increases in the countryside. People use Spanish in conversations with strangers who are well dressed but Guarani with those who are poorly dressed. Due to an educational value attached to Spanish, parents may encourage their children to improve their skills in this socially preferred language. When out of their country, Paraguayans may deliberately speak Guarani to express their distinctiveness from other Spanish-speaking people.

In this language situation, natives' different and even ambivalent feelings toward the two languages were identified (Rona, 1966; Rubin, 1978). Because Spanish is a prestigious language, some bilingual individuals tend to see monolingual Guarani speakers as being inferior. On the other hand, there is a common attitude that anyone who cannot speak Guarani is not a real Paraguayan. Most of the natives, who take pride in their own language, are irritated by the idea of Guarani as being unsophisticated because it is a "mere" Indian language. At the same time, they somehow feel that Spanish is indeed a more elegant and better language than Guarani. One step to change this language attitude was taken in 1978 when the government decided to authorize the use of Guarani in primary education (Rubin, 1978). The linguistic situation in Paraguay may seem to be diglossic for some Paraguayans who consider these two languages in terms of their functions only, but it is certainly not so for others who find the 
relationship of two languages problematic (Wardhaugh, 1990).

A speaker's social and cultural identity is also an important factor of code switching. Gal (1979) claimed that the identity of participants needs to be known to predict code choices. In her study of an Austrian town located in Austrian-Hungarian border, where Hungarian was used in most of the activities until recently, she discovered how the process of industrialization effected a change in locals' language, creating a shift from Hungarian to German. She claimed that social changes from a "peasant economy" to a more industrialized one increased prestige of German which is the state language and used in industrial activities. Consequently, the value of Hungarian declined and it became stigmatized. Individuals who seek higher status favor speaking German and reject the Hungarian peasant life style and its language.

Labov investigated the code varieties which were associated with social class in his New York studies. He (1966) reported a phenomenon in which the lower middle-social class people consciously produced r-pronunciation during the investigation knowing that $r$-pronunciations were prestigious and the lack of the r-sound was common among the lower class group. Labov explained that the lower middle-class people out-performed the upper middle-class group in order to project an image of themselves as sophisticated speakers. From the results of his study, Labov discovered how various 
speech styles were spoken in different social class, how people evaluated these variations, and how it affected people's choice of a certain style. Although his findings have not been statistically tested, they confirm that linguistic change "co-varies" with social change and thereby establish the social nature of language (Wardhaugh, 1990; Williams, 1992).

According to Blom and Gumperz (1986), language change or choice cannot always be understood only in terms of linguistic analysis without knowing the norms or values embedded in the society that governs speech behaviors. They examined the relationship between standard Bokmal and one dialect, Ranamal, in a small village in Northern Norway. They found that the meaning of both codes differed depending on ingroup-outgroup interactions. "This social significance of dialect can only be understood by contrast with the meanings which locals assign to the standard, the language of nonlocal activities" (Blom \& Gupmerz, 1986, p. 433). Their investigation demonstrated the importance of social meaning for the study of language in society.

I have discussed the varieties of codes and speakers' selections of codes in various speech communities. Although accounting for code switching in every case of conversation is out of the question, it is possible to interpret its structures and functions once they are observed. 
Structures of Code Switching

Blom and Gumperz (1986) distinguished two types of code switching in their investigation in Norway: situational and metaphorical code switching. Situational code switching assumes "a direct relationship between language and the social situation" (p. 424). In this case, one language variety is used in a certain situation and another in a different situation. Participants alter their language based on the definition of communication situations. Metaphorical code switching occurs when participants redefine role relationships with others such as formal to informal, official to personal, serious to humorous, and deference to solidarity. Metaphorical code switching is deeply interwoven into interpersonal relationships among participants.

According to Saville-Troike (1989), another dimension to be distinguished is the discursive locations where code switching takes place. These are referred to as intersentential and intrasentential switching. Intersentential switching occurs between sentences or speech acts while intrasentensial switching occurs within a single sentence. The following example is intrasentensial switching by a bilingual Chinese child (Saville-Troike, 1989, p. 63):

Neige fox yoa chi ta [that] [want eat him] (That fox wants to eat him.)

[telling a story] 


\section{Functions of Code Switching}

Previous research has identified various functions of code switching. Gumperz (1982) suggests seven conversational functions of code switching. These are: quotations, addressee specification, interjections, reiteration, message qualification, and personalization versus objectivization. In some cases, code switching occurs as direct quotations. The following statement is Hindi-English speaker's quotation example (Gumperz, 1982, p. 76):

I went to Agora, to maine əpne bhaiko bola ki (then I said to my brother that), if you come to Delhi you must buy some lunch.

Addressee specification is a switch that serves to direct the message to one of several possible addressees. Code switching is occasionally used to mark an interjection. The following conversation by Chicano professionals illustrates this function (Gumperz, 1982, p. 77):

A: Well, I'm glad I met you.

B: Andale pues (OK, swell).

Reiteration refers to the fact that after stating a message in one language, a speaker may repeat it in another:

Spanish-English. A Chicano professional: Nothing but Spanish. No hablaban ingles (they did not speak English).

Hindi-English. Father calling his son while he is walking in a train compartment:

Keep straight. Sidha jao [louder] (keep straight).

Following a copula or linking verb, code switching also occurs to qualify constructions such as sentences, 
complements, or predicates. This function of code switching is called message qualification (Gumperz, 1982, p. 60):

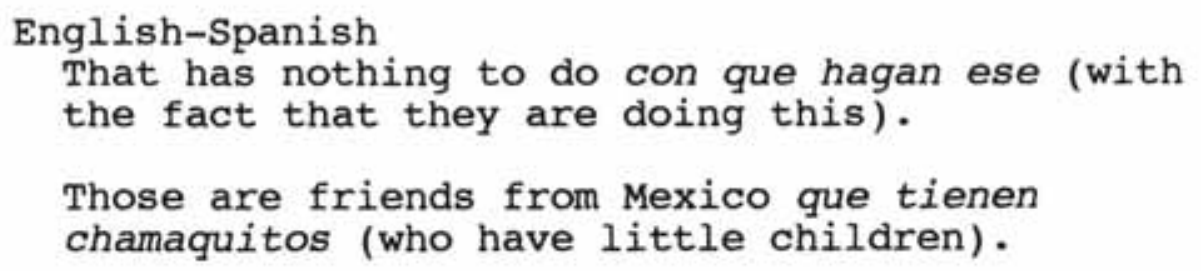

Finally, Gumperz presents a more complicated function of code switching: personalization versus objectivization:

The code contrast here seems to relate to such things: talk about action and talk as action, the degree of speaker involvement in, or distance from, a message, whether a statement reflects personal opinion or knowledge, whether it refers to specific stances or the authority of generally known fact (Gumperz, 1982, p. 80).

Several other functions are suggested by Saville-Troike (1989). She claims that code switching serves to soften or strengthen requests or commands. Speakers may also intensify or eliminate ambiguity by saying something twice in a different language. They may switch codes in order to produce humorous effects. Sometimes, the lexical need determines code choice; that is, a speaker knows the desired expression only in one language or the expression in one language cannot be translated into another. In some cases, code switching functions as an avoidance strategy, either if certain forms are incompletely learned in one of the languages, or if one language requires a social status distinction a speaker does not wish to make. Finally, Saville-Troike suggests that the function of repair strategies occurs when speakers realize they have been using 
an inappropriate code.

Some scholars contend that language serves to maintain social boundaries separating one community from another (Gumperz, 1982; Gumperz \& Cook-Gumperz, 1982). Blom and Gumperz interpreted this function in regard to ingroup vs outgroup role relations. Language choices governed by group membership are reflected in language. One language code demonstrates "we" type group identification and is used for ingroup or informal activities, while the other is "they" oriented and is used for outgroup or formal interactions. Maintaining speakers' group identity, solidarity, or distance is considered an essential performance function of code switching.

However, according to Heller (1988), code switching is a contradiction to the idea of separation. Although social separation implies the existence of social boundaries regulating or constraining linguistic resources, the existence of code switching suggests that there are individuals who have access to all these linguistic resources. Not only do they have such linguistic access, Heller claims, but also they have access to multiple role relationships. In her study of social separations in FrenchEnglish contact in Canada (1988), she found the importance of code switching in "leveling" social group boundaries:

despite social separation of language in the wider community, certain individuals...find themselves in domains which are otherwise mutually exclusive, or they must act as brokers 
in situations which form the interface between mutually exclusive domains (p. 17).

Another study in Catalonis by Woolard (1989), also found that code switching by a popular entertainer helped to ease group boundaries between speakers of Castilian and Catalan, serving as a boundary leveling rather than a boundary maintenance function. This function of code switching as an interaction strategy does not eliminate all of the group separations in society, but it serves to loosen some of the boundaries existing among people (Heller, 1988; Woolard, 1988).

\section{SUMMARY}

The ethnography of communication focuses on the variety of codes available in a speech community together with a speaker's communicative competence in selecting an appropriate code depending on the occasion. Code choices are governed by cultural values and norms within a community and therefore manifest how social structures and languages interact each other. Particular code switching forms and features have also been identified. Investigating "the use of language in the conduct of social life" (Bauman \& Sherzer, 1975, p. 96), specifically code switching in this instance, the ethnography of communication contributes to an understanding of human behaviors in social affairs. 
CHAPTER III

\section{HISTORICAL BACKGROUND OF THE RESEARCH FIELD}

Before I present the research design, Okinawan history and language variations need to be explained in order to provide background information and to make the research purpose clear.

\section{OKINAWA}

Okinawa is a Japanese prefecture located between (southern part of Japan) and Taiwan. Geographically, the prefecture of Okinawa consists of four major islands (Okinawa, Miyako, Ishigaki, Iriomote) and many smaller islands. The largest and most important island is okinawa which is about $70 \mathrm{miles}$ long and an average of 8 miles wide. The capital of the prefecture, Naha, is on this island. The total population is now reaching 1.3 million. In Japan, Okinawa is the only prefecture with semi-tropical weather. The summer is long and hot with temperatures approaching $90 \mathrm{~F}$ and relative humidity averaging 80 percent. In this climate, sugarcane and pineapples are the major agricultural products. The main industry is tourism. Okinawa's great number of popular beach resorts attract over 2 million mainland Japanese every year. 


\section{Okinawan history}

Historically, Okinawa was an small independent country called the Ryukyu kingdom which had a relationship mostly with China. Ryukyu's trading relationship with Japan became prosperous in the late fourteenth century. Japan was willing to trade with Ryukyu because this small country prospered as a trading nation which traded in products from China and southeast Asian countries. Although Ryukyu, itself, was an independent kingdom, its political status in relation to its two powerful neighboring nations, China and Japan, was ambiguous. This ambiguity led to both countries' perspective that Ryukyu was their territory (Miyagi, 1983). As a reward for putting down a revolt against the then shogun, Muromachi shogunate, the Japanese feudalistic government (1338-1573), granted Ryukyu to the Shimazu clan of Satuma (the present Kagoshima prefecture) in 1441 (Miyagi, 1991).

Even though it was not a substantial reward, Shimazu tried to control Ryukyu, making demands without consultation with the people of the Ryukyu kingdom. Considering its own political independence and the long relationship with China, Ryukyu sometimes refused these demands.

The Shimazu clan invaded Ryukyu in 1609 , following accusations that Ryukyu had not been obedient to the shogunate. They had little difficulty in conquering the kingdom and capturing its king, who was taken prisoner to Satuma and kept in exile for two years. After the invasion, 
Ryukyu was controlled by the Shimazu clan and forced to pay tribute to the Tokugawa shogunate (1603-1867). While experiencing gradual influences from Japanese culture, Ryukyu maintained its social system as if it were a foreign country within Japan (Miyagi, 1991; Hokama, 1991).

In 1867, the fifteenth Shogun Yoshinobu Tokugawa returned the political power of Japan to the Emperor of Japan, ending the Tokugawa shogunate and its isolationism which had lasted for 260 years. This also marked the beginning of the Meiji government whose aim was to catch up with civilized Western nations.

Under the Meiji Restoration (1868), outright Japanese annexation of Ryukyu occurred and its name was changed to Okinawa. This was called "Ryukyu Shobun" (the disposal of Ryukyu). "Ryukyu Shobun" was necessary for Japan to promote the unification of the country and enhance its national prestige against China by legitimatizing the administration of Okinawa which had previously enjoyed independence.

Soon Japan embarked upon its political ambition to expand territory in the Sino-Japanese War (1889-1895), the Russo-Japanese War (1904-1905), and finally World War II. During the first months of World War II, Japanese troops were victorious. However, as the war went on and American troops gradually come toward Japan from the southern Pacific, feelings of unease and apprehension grew among the Japanese, especially the okinawans. They predicted that sooner or 
later, there would be a great battle on their island. Every available Okinawan was conscripted, age limits were expanded, and those who were held unfit for military duty were drafted into a work force (Oshiro, 1989). The strength of the Japanese army on Okinawa was roughly 120,000 soldiers which consisted of 30 percent drafted Okinawans, including high school boys as soldiers and girls as war nurses (Oshiro, 1989). On April 1, 1945, 183,000 American troops landed on Okinawa. This was the okinawans' historic encounter with a new dominant force from the West: the United States.

Okinawa was known as the last battlefield of World War II (Oshiro, 1989). The battle of Okinawa, named "Typhoon of Steel" by the Okinawans, killed more than 200,000 people between April 1 and June 23. Causalities numbered 12,520 U.S. soldiers, 65,908 Japanese soldiers, 28,228 Okinawan soldiers, and 94,000 Okinawan civilians (Idaka, 1986). The actual number of Okinawan deaths from the war overall is still unknown. It is estimated that one out of four okinawan civilians were lost when those who died of disease and starvation following the battle are included (Oshiro, 1989). After the war, America found Okinawa's geographic location to be militarily strategic. America acquired the trusteeship of Okinawa in the 1951 San Francisco Peace Treaty which also allowed Japan to be free from the trusteeship of the United Nations. Since then, American military bases in Okinawa have played an important role in the Korean War, the Vietnam War, 
and the Cold War (Kikumura \& Kinjo, 1989).

The administrative policies implemented by the U.S. military were based on paternalism (Miyazato, 1986; Miyagi, 1981) which treated the local people unequally. This led to an anti-military movement in the okinawan society and as a result, the administration reverted to Japan on May 15, 1972. Once again Okinawa became part of Japan. However the reversion did not end the difficulties, for the U.S. retained the right to keep bases on Okinawa as part of the Mutual Security Treaty (Miyagi, 1983).

Twenty percent of the island is occupied by the U.S. Marines, Navy, Army, and Air Force units, which number 52, 349 military personnel and its dependents. With one percent of the land area and one percent of the population of Japan, Okinawa has 75 percent of the exclusive U.S. military facilities in Japan (Kikumura \& Kinjo, 1989). Since Okinawa is an small island, the military bases cannot be located outside cities or towns but are inside of them. According to Kikumura and Kinjo (1989), this close physical proximity to the base causes problems: terrible noise pollution from the combat planes taking off and landing; educational disadvantages among neighboring elementary schools; and the dangerous military exercises which threaten the local people while destroying the natural environment. Whenever the Okinawans request the withdrawal of the U.S. bases, the Japanese government justifies their the presence by 
emphasizing how important it is to keep them for national security (Kikumura \& Kinjo, 1989).

Despite conflicts between the local people and the U.S. military that still take place, the presence of the U.S. bases for 47 years has been creating new social aspects in Okinawan society, providing okinawan-American interactions, building up an Americanized atmosphere in some cities, and producing intercultural marriages every year.

\section{LANGUAGES IN OKINAWA}

Designed to examine the social meaning of language in Okinawan society, this study approaches Japanese, English, and the Okinawa dialect which is one of the regional Okinawan dialects spoken on the island of Okinawa. In order to provide information about the linguistic situation in this study, the history of language and language variations in Okinawa needs to be explained.

\section{Lanquages in Japan}

Historically, Japan had large language diversification with extremely rich dialect variations (Shibatani, 1990). These language variations often caused problems in communication among speakers of different dialects. Because of these difficulties, the Japanese developed the concept of a standard language under the Meiji Restoration (1868). At that time, Japan was desperate to join the Western world, 
starting new systems in its politics, economy, and education. Therefore, having a unified common language was one of the national goals. However, this contrived standard form of Japanese was never established. Instead, the dialect in Tokyo, where governmental power is centered, became standard Japanese (Shibatani, 1990).

\section{Okinawan Dialects}

In most linguistics studies, dialects spoken on the Okinawan islands are usually described as "Ryukyuan dialects," taken after Ryukyu, the old name of Okinawa. In order to maintain consistency in this paper, I will refer to Okinawan dialects as a general term for dialects spoken in Amami, Okinawa, Miyako, and Yaeyama islands. [Note: Amami politically belongs to Kagoshima prefecture but linguistically belongs to Okinawa.]

As mentioned earlier, the prefecture of Okinawa consists of many islands. Dialects spoken on these islands are divided into four groups. These are the Amami dialect, the Okinawa dialect, the Miyako dialect, and the Yaeyama dialect. The diversity among these dialects is considerable, making them unintelligible to each other (Shibatani, 1990). [Note: The reader should not be confused by "Okinawan dialects" which include every regional dialect and "the okinawa dialect" which is a dialect spoken only on the island of Okinawa.] 
In addition to the internal diversity of Okinawan dialects, there is also a greater difference between Okinawan dialects and mainland dialects (Hokama, 1981; Uchima, 1983; Nakamoto, 1983). At the time Okinawa and its islands were unified under the Ryukyu kingdom, the language spoken there was called Ryukyuan as if it were a different language from Japanese (Shibatani, 1990). The first linguistic study of Okinawan dialects is found in an essay entitled "Essay in aid of a grammar and dictionary of the Luchuan (Ryukyuan) language" by Basil Hall Chamberlain in 1895. Chamberlain claimed that Ryukyuan was a sister language of Japanese. Most linguists now believe that Japanese can be divided into mainland dialects and Okinawan dialects (Kokuritsu Kokugo Kenkyujo [KKK, National Japanese Language Institute], 1984). Languages in both areas emerged from proto-Japanese (Hattori, 1976). Despite sharing the same foundation, Okinawan dialects developed their own phonological systems, syntax, and lexicon (KKK, 1984; Hokama, 1981; Nakamoto \& Nakamatsu, 1984). Consequently, these characteristics made them unintelligible to the speakers of mainland dialects. Figure 1 illustrates the relationship between mainland dialects and Okinawan dialects.

As Figure 1 shows, dialects in the mainland Japan and Okinawa emerged from proto-Japanese. A great number of regional variations were derived from each dialect. Those areas which have local dialects in Japan use standard 


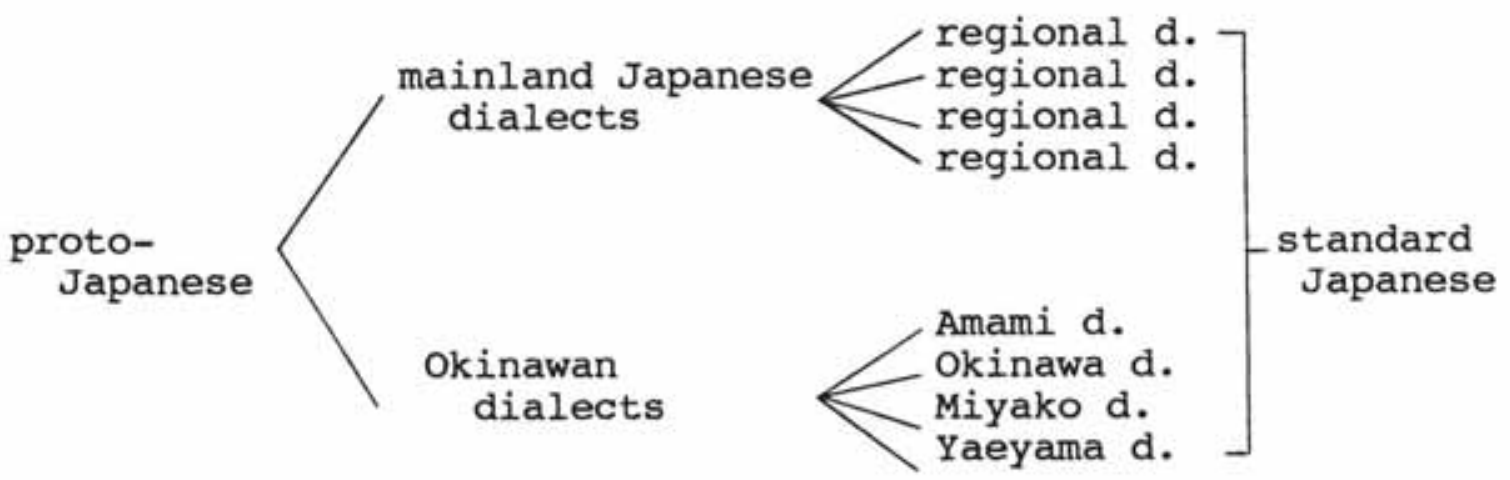

Fiqure 1. The relationship between Japanese and Okinawan dialects. Adapted from Hattori 1976.

Japanese and their dialects to a lesser or greater degree. Yet the differences between standard Japanese and Okinawan dialects were considerably greater resulting in seemingly different languages. Hattori (1960) states that differences between mainland dialects and Okinawan dialects are similar to those of English and German.

\section{Japanese Lanquage Planing in Okinawa}

In order to overcome language barriers and create loyalty for the Japanese Emperor, the Meiji government carried on the rapid Japanization of Okinawa. The urgent need to adopt Okinawa into the unified nation led to an extreme education policy of fostering standard Japanese. This policy was designed to replace Okinawan dialects with standard Japanese for the purpose of creating Okinawans ' self-identity as Japanese (Hokama, 1981; Agarie, 1983; Nakamatsu, 1984; Ikemiyagi, 1980). Figure 2 illustrates the language transition process in Okinawa. The percentages 
indicate how discourse in dialects declined as Japanese was increasingly spoken by the Okinawans.

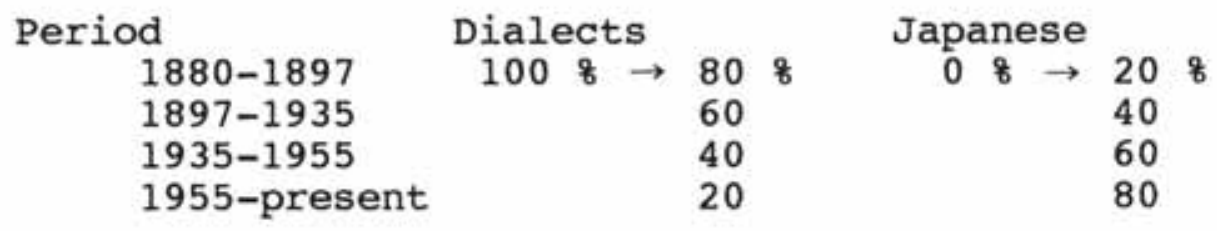

Figure 2. The language transition process. Adapted from Nagamori, 1979.

The Japanese language policy in education began in the Meiji era (1868-1912), continued through the Taisho era (1912-1926), and into the first few decades of the Showa era (1926-1989). Okinawan dialects were considered unsophisticated languages and were prohibited in educational settings. In school, there was a name tag called "Hogen Fuda" (the dialect tag). Students who used dialects had to wear this tag as punishment through public humiliation until they found others' violating the rule by speaking dialects. Then they could pass the tag to the next victim. The quick, easy way of getting rid of this tag was to pinch somebody hard in order to make this person utter "Agaa!" ("Ouch!" in Okinawan dialects).

The enforcement of standard Japanese was strongly promoted in 1939 when the Okinawan local government expanded the Japanese speaking policy to the domestic sphere of Okinawans' lives (Hokama, 1981). This language policy brought a famous heated dispute called "Hogen Ronso" (the 
dialect controversy) between people who criticized the policy and the local government. The issue in question was not only whether Okinawans should speak their indigenous language but it was also deeply related to the particular social circumstance of Okinawa as a Japanese prefecture. Considered to be an underdeveloped region in Japan, Okinawa had been struggling to attain the same level of modernization that the mainland had achieved (Hokama, 1981). Realizing its backwardness, the Okinawan government supported Japanese language planning which could encourage social, political, and economical development.

Another important influence in promoting this language planning at this historical moment was Japan's involvement in World War II (Hokama, 1981; Agarie, 1983). With its aim to mobilize all Japanese citizens for an upcoming war, Japan's nationalism required okinawans to pledge their loyalty to the Emperor. The Japanese government utilized the language planning to propagate patriotism in Okinawa.

Okinawans accepted Japanization as a way of improving their society. At the same time, they experienced selfdenial in losing their indigenous language (Agarie, 1983; Hokama, 1981). In this specific prefecture of Japan, the different political intentions of mainland Japan and Okinawa were fused into the language planning which created a dilemma among Okinawan civilians.

As Figure 2 shows (see p. 33), Okinawans were able to 
use both dialects and Japanese at this phase of the language planning. Yet speaking dialect, which was unintelligible to the Japanese, created tragedy in World War II on the island of Okinawa. During the battle of Okinawa, the Japanese soldiers murdered local people who were falsely accused of being spies. Since the Japanese soldiers could not understand the local language, it created fear and paranoia that the okinawans might have been communicating secretly with the Americans.

\section{Language Transition and its Consequences}

As a result of the education policy started by the Japanese government, which lasted approximately one hundred years, Japanese is now spoken throughout the Okinawan islands (Nakamatsu, 1984). Although the dialect tag is no longer used in educational settings, school curriculums continue to be taught in standard Japanese. Mass media also plays an important role in conveying standard Japanese throughout the islands. Printed materials such as newspapers, books, and magazines are written in standard Japanese. Actually, Okinawan dialects cannot be perfectly described by the Japanese writing system due to the phonological features that standard Japanese does not have (Nohara, 1983). While standard Japanese has successfully established its prestige in okinawan society, Okinawan dialects have been vanishing (Agarie, 1983; Hokama, 1981). 
The transition of language variation in Okinawa was predicted by Yabiku in 1964. This local linguist stated that the first generation who acquired a Japanese education spoke only Okinawan dialects. The following second and third generation gradually learned Japanese and became fluent in it. Finally, the members of the fourth generation speak Japanese more frequently than dialects. Agarie (1991) expanded Yabiku's prediction and claimed that the children in contemporary Okinawan society who are raised by parents of the fourth generation almost exclusively speak Japanese and cannot understand much of the Okinawan dialects. When this fifth generation becomes parents, there will be no environment to provide dialect acquisition at home. The implication of this, he argues, is that the extinction of Okinawan dialects is inevitable in the near future.

Linguistic studies in Okinawa mostly center upon dialects due to their near extinction as the number of the old people who can still fluently communicate in dialects decreases. Even though Okinawans' consciousness for their local endangered language has been recently raised and some efforts have been made to preserve their language, dialects are nevertheless declining.

Contact between both languages has played a major role in destroying Okinawan dialects (Nakamatsu, 1984; Hokama, 1981; Agarie, 1983). However, in the process of language contact in Okinawa, dialects have affected standard Japanese 
and have blended into it by formulating a creole-type language called "uchinaa-yamatoguchi" (Okinawan-Japanese) (Agarie, 1983). Okinawan-Japanese is a double structured language which is created from standard Japanese with some features of the Okinawan dialects (Nakamatsu, 1984). Along with rapid cultural changes through the nineteenth century to the twentieth century, the Okinawans developed OkinawanJapanese which sounds different from standard Japanese due to phonological, syntactic, and lexical influences from dialects (Nakamatsu, 1984; Agarie, 1983). Due to the regional

varieties in Okinawan dialects, Okinawan-Japanese might also exhibit internal variations depending on which dialect has influenced Japanese.

The language situation in modern Okinawa is therefore complicated. The current generation picks up this double structured language from their everyday environment, learns standard Japanese from mass media, and hears pure dialects spoken by the old people. Yet these linguistic varieties may be reduced and simplified in the future. Some local scholars wonder whether the Creole, Okinawan-Japanese, will acquire the status as a local language, or if it is only a temporary language destined to be replaced in time by standard Japanese (Komesu, 1991; Agarie, 1991). At this point, the future of okinawan-Japanese cannot be clearly predicted and it has not been fully studied; only time and extensive research will yield answers on this issue. 
Summary of Lanquages in Okinawa

I have discussed language transition and variations within the Okinawan speech community. Although it is spoken throughout Okinawa, the status of Okinawan-Japanese is still ambiguous due to a lack of a clear linguistic distinction between Okinawan dialects and Okinawan-Japanese. This ambiguity may create some problems for the reader in understanding the actual code switching analysis unless the approach taken in the thesis is clarified at this point.

The code switching activities examined in the present study take place on the island of okinawa and the main research subjects, Ken and Masumi, speak the Okinawa dialect. They acknowledge themselves as "trilingual." The DJs' publicity does not include the issue of Okinawan-Japanese (see Shinjo, p. 2). Taking the view of the native speakers, I treat their particular code switching activities as being tri-code: Japanese, English, and "the Okinawa dialect." The Okinawan-Japanese Creole focused on in this study is the Creole produced during language contact between Japanese and the Okinawa dialect and is the creole form spoken on the island of okinawa. Yet, for purposes of this study, I define Okinawan-Japanese as an internal variety of dialect, not a separate code. In other words, this study includes OkinawanJapanese as part of the Okinawa dialect. Although it is possible to distinguish among four code forms, for the purpose of the current study, the "trilingual" strategy is 
useful because it reflects the native speakers' perspective of their own linguistic performance and because OkinawanJapanese functions as the commonly spoken local language among Okinawans. 


\section{CHAPTER IV}

\section{METHODOLOGY}

Justification of the research design, framework of the study, issues of validity and reliability, and research procedures are presented in this chapter.

\section{QUALITATIVE RESEARCH METHODS}

The choice of qualitative or quantitative methodology depends upon the purpose of the investigation and must be made according the nature of the research questions (Frey, Botan, Friedman, \& Kreps, 1990). While the quantitative approach is designed to test a hypothesis or theory built upon a predicted cause and effect relationship of the phenomenon being studied, the goal of qualitative research is to isolate and define factors consisting of the phenomenon during the course of study (McCracken, 1988). In other words, qualitative research investigates a naturally occurring phenomenon in order to develop descriptive frameworks heuristically at the present, and theoretically, later (Philipsen, 1982).

In this study, the questions being asked seek to ascertain the meaning of the communication behavior but not to quantify specific linguistic features of the code 
switching. Therefore, research questions are not stated as cause and effect relationships.

Philipsen (1982) presents one type of naturalistic investigation called the qualitative case study, that is structured as in situ, openly-coded, non-manipulative, and participatory research. Unlike quantitative research, which is often conducted in the laboratory, qualitative research is most often conducted "互 $\underline{\text { situ, }}$ in the settings and at the times which are usual contexts for the subject's actions" (Philipsen, 1982, p. 5-6). The code switching in this study occurs in natural conversations in a regularly scheduled radio program. I did not attempt to manipulate the environment. Instead, I went into the field, observed the phenomenon, and experienced it with the participants of my investigation.

Not having "ready-made theoretical categories" (Bulmer, 1979 , p. 664) to explain this particular phenomenon, I utilized Hymes's descriptive-theoretical framework (1986): the ethnography of communication. It guided me in initial data collection and data analysis. The actual features and patterns of the code switching could not be predetermined but emerged and were categorized during field work. Simultaneously, review of analytic categories from previous literature on code switching were utilized heuristically to aid in categorization of code switching and to sensitize me the particular speech behavior in this study. Information 
from previous studies assisted me in collecting my observational data. Additional data also emerged during the course of the investigation. Each source of data interacted and informed each other (Bulmer, 1979). Therefore, the qualitative case study provided the most appropriate approach to the code switching activity under investigation.

\section{THE ETHNOGRAPHY OF COMMUNICATION}

Ethnography originates from the Greek word ethnos which means a tribe, race, or nation, and graphos which means something written down. Thus, Philipsen (1989) states, "an ethnography is a description, a written report about a particular people" (p. 256). Ethnographic research is essentially a field study which "depends on watching people in their own territory and interaction with them in their own language, on their own terms" (Kirk \& Miller, 1986, p. 9). It reports cultural particularity rather than generality and "tells an interesting story" (Philipsen, 1977, p. 46).

The ethnography of communication is naturalistic research (Frey, Botan, Friedman, \& Kreps, 1991) because it is designed to capture culturally patterned communication modes which take place in people's everyday life. According to Philipsen (1977), the nature of naturalistic research, which lacks experimental control over the research objects, requires that the ethnography of communication studies should be conducted in both a linear and non-linear way. Linearity 
of research design refers to "the specification, in advance of data collection, of both a purpose for research and the steps to be taken to serve the purpose" (Philipsen, 1977, p. 45). Philipsen (1977) explains:

the ethnographer finds a middle way between rigid linearity and deliberate non-linearity. Specifically, the ethnographer should, in advance of his field work, specify as explicitly as possible, (1) the phenomenon to be described, (2) conceptual linkages of that phenomenon to the process of communication, and (3) the descriptive framework he will use to study the phenomenon selected. He should leave unspecified, as objects of exploratory inquiry, (4) the particularities of the phenomenon in a given social field, and (5) the adequacies of the descriptive framework used (p. 45).

Ethnographers, of course, should specify the concepts related to the phenomenon as well as the research processes of the investigation that they use prior to conducting their actual research. Simultaneously, they should acknowledge that their conceptual concerns do not guarantee to provide "linearity" as the research progresses during the field work. Due to this uncertainty, the researcher should not specify "the particularities of the phenomenon of interest for a particular social world of setting" (Philipsen, 1977, p. 48). Philipsen (1977) contends that one purpose of ethnography is to refine a descriptive framework that a researcher applied heuristically; a descriptive framework, which initially guided a researcher, itself become an object of study at some point during the investigation.

The strategies in exercising this heuristic inquiry are 
etic and emic approaches to the phenomenon being studied. An etic account provides a researcher with a preliminary grid to investigate a communication phenomenon while an emic account allows participants to bring to the research the natives' own explanations and conceptualizations of their behaviors within a phenomenon (Hymes, 1974). Hymes (1974) states "Ethnographic objectivity is intersubjective objectivity, but in the first instance, the intersubjective objectivity in question is that of the participants in culture" (p. 11). Functions of communication may have specific meanings to individuals as well as cultures and may require specific identifications in all cases. The ethnographer must bear in mind that an initial etic grid only serves to help to delineate and perceive possible types of functions that might exist in the phenomenon under investigation. A constant reference to emic accounts brought by participants is required.

Participant observation is an important methodological technique of ethnography. Denzin (1988) defines it as follows:

Participant observation is a commitment to adopt the perspective of those studied by sharing in their day-to-day experiences (p. 156).

In order to collect data about the phenomena they are studying, ethnographers use multiple methods in their approach of participant observation (Frey, Botan, Friedman, \& Kreps, 1991). Multiple methods include: going into a field, 
observing ongoing events, interviewing informants, analyzing documents from the past, recording interactions, and studying "cultural artifacts," that is, recordings or transcriptions of interactions (Frey, Botan, Friedman, \& Kreps, 1991; Denzin, 1988). Denzin (1988) states that participant observation is a field strategy that "combines document analysis, interviewing of respondents and informants, direct participation and observation, and introspection" (p. 158).

Hymes (1986) claims that speech is the important unit of analysis in the ethnography of communication. He defines speech events as activities that are "directly governed by rules or norms for the use of speech" (p. 56) and presented the mnemonic SPEAKING formula to explain events. These components represented by mnemonic SPEAKING include: Setting and Scene (S), Participants (P), Ends (E), Act Sequence (A), Key (K), Instrumentalities (I), Norms of Interaction and Interpretation (N), and Genres (G).

Setting refers to time and place of a speech act, while Scene refers to "psychological settings" or cultural definition of an occasion. Participants includes Speaker/Sender, Addresser, Hearer/Receiver/Audience, and Addressee. Ends refer to goals for the interaction and outcome of the interaction. Message form (how something is said) and content (what is said) are components of the Act Sequence. Key refers to the tone, manner, or spirit in which 
an act is spoken. Instrumentalities have two components: Channel, the medium of transmission of speech and Form of Speech, the language, dialect, code, varieties or registers. Norms of Interaction and Interpretation imply that all rules governing speech have a normative character to orient participants' interaction and interpretation. Genres are categories such as myth, tale, riddle, proverb, prayer, or lecture and often coincide with speech events. However, they must be treated as being "analytically different" (Hymes, 1986, p. 65). The ethnographer's concern is for the interrelationships of these components which create a speech event.

\section{VALIDITY AND RELIABILITY}

\section{Validity}

Validity concerns the accuracy of research findings. Appropriate strategies for data collection and analysis techniques by ethnographers are crucial to increase validity (LeCompte \& Goetz, 1982).

In this study, my status as an insider of okinawan society provided me both an advantage and disadvantage. Being familiar with local culture, I had access to local understanding and interpretations of the ongoing phenomenon by sharing cultural experiences in ways an outsider might only achieve with great difficulty (Saville-Troike, 1989). However, discovering patterned behavior, which operates 
primarily out of awareness for a native investigator, creates difficulty in maintaining analytic distance (Saville-Troike, 1989). In order to avoid "blinding familiarity" (McCracken, 1988 , p. 23) caused by my cultural adaptation to Okinawan society, maintaining a distance from the phenomenon was important for the validity of this study.

One way to increase validity in this investigation was triangulation, that is, taking different perspectives of a single phenomenon into consideration and allowing plausible interpretations based on different participants' perspectives (Sevigny, 1981). Comparing four types of people, i.e., code switchers, local listeners, the director of the program, and some of the older local people provided me multiple ways to look at the phenomenon in addition to my own perspective as a native researcher.

Ethnographers often triangulate their findings by using various methods to collect data in order to reduce threats to validity (Frey, Botan, Friedman, \& Kreps, 1990). Multiple methods used in this study include observations, transcriptions, and interviews. These were used to establish convergent validity, that is, the degree to which two or more different measuring procedures measure the same things (Katzer, Cook, \& Crouch, 1982).

Another threat to validity is researcher effects or "the influence of a researcher on the people being studied" (Frey, Botan, Friedman, \& Kreps, 1990). I conducted an interview 
with Ken and Masumi at the very last phase of the data collection process so that I could avoid possible influence upon their code switching activities.

For ethnographers who study a certain form of verbal communication, ability to speak the subjects' language is important (Saville-Troike, 1989). As a person who grew up in Okinawan society and with the experiences of living in the United States, I have access to all languages which are spoken by the DJs. This linguistic access provided me more accurate understanding of what was said in the program and aided in interpretation of the code switching phenomenon under investigation.

\section{Reliability}

Reliability is concerned with consistent and stable research findings which lead to similar outcomes when the study is replicated (LeCompte \& Goetz, 1982). Those findings are relatively easy to obtain when the research procedure is simple, routine, and highly standardized (Jorgensen, 1989). Jorgensen claims that it is not appropriate to apply the conventional notion of reliability in a study which deals with a naturally occurring phenomenon with multiple methods in an open-ended, in-depth research manner. Discussing the methodology of the ethnographic participant observation, he explains that reliability is highly interrelated with validity and is highly concerned with "dependable and 
trustworthy finding" (p. 37). In this study, I approached reliability as conceived by Jorgensen's definition. The following steps were employed to insure dependability and trustworthiness of the research findings.

In this study, translations in transcriptions were checked by a Japanese-English bilingual university professor. In order to avoid idiosyncrasy and heavy personalization of the study, constant comparison of the different groups of interviewees' perspectives was needed (LeCompte \& Goetz, 1982; Glaser \& Strauss, 1966). I was also obliged to provide detailed, sufficient description of strategies in data collection and the analysis techniques (Jorgensen, 1989) so that it would increase replicability of this study (LeCompte \& Goetz, 1982). Replication may be impossible if the constructs, definitions, or unit of analysis which informed the original research are idiosyncratic or poorly delineated. In other words, replicablility is enhanced by carefully outlining the theoretical premises, defining constructs that inform and shape the study, and providing precise identification as well as thorough description of strategies used for data collection and analysis (LeCompte \& Goetz, 1982). I attempted to make the best effort to identify and provide these elements in this investigation. 


\section{RESEARCH PROCEDURES}

The following section deals with data collection, sampling, and interviewing procedures in order to map out the research process.

\section{Data Collection Procedures}

Data were collected from observations in the studio of FM Okinawa and the Book Box station, transcriptions of the radio program, and interviews with Ken and Masumi, listeners, the director of the program, and older locals.

Transcriptions. The radio program, "Pop'n Roll Station" was tape recorded during a three-month period beginning in June 1991. Thirty tapes were collected during this period. Among them, nine tapes were selected for transcription. Since the program has slightly different schedules depending on the day of the week, I chose three tapes of each day (Monday, Wednesday, Friday) in order to include all possible features in transcriptions. Nine tapes of two-hour duration, eighteen hours total, is a reasonable and manageable data base for the study. In search of additional support for the code switching patterns found in these nine tapes as well as any evidence of deviant cases, partial transcriptions were taken from the rest of the twenty-one tapes.

The notation system in transcription is adopted from Watanabe's dissertation (1990) (for additional information on the notation system, see Appendix C). In the transcriptions 
presented in this study, Japanese is in capitalized Roman letters with appropriate English translations. Okinawan dialect and Okinawan-Japanese including accents are in capitalized and italicized Roman letters with italicized English translations. Translations were checked by a Japanese-English bilingual university professor in order to establish reliability (see p. 49).

Observations. I observed program fans for six nights, twelve hours total, in the studio of FM Okinawa on Mondays and Wednesdays and in the Book Box station on Fridays. During the first phase of data collection, my status was a complete observer who did not interact with people but observed and took field notes.

After this two-week observation period, I contacted the director of the show to ask permission to interview listeners at FM Okinawa and to obtain access to Ken and Masumi. This procedure was needed to make my position clear at FM Okinawa. In the first meeting with Ken, Masumi, and the director, I explained that my research was a requirement of PSU masters program but did not mention that this would be a code switching study because I did not want to have any possible influence upon the DJs' verbal behaviors by revealing the research theme at that point.

Interviews. After the meeting, I was allowed to interview people at FM Okinawa, including program fans, the DJs, and the director. I also interviewed a small number of 
older Okinawans in order to compare the different age groups' perspectives for the DJs' language behaviors.

\section{Sampling and Interviewing Procedures}

I selected the following people as my interviewees for this study.

Code Switchers. For the purpose of this study, the criterion for the selection of code switchers was persons who speak Japanese, English, and the Okinawa dialect in broadcasting. For their trilingual code switching character, the two DJs, Ken Robillard (age 30) and Masumi Rodriguez (age 26), are the main subjects of this investigation. They are bicultural individuals who acquired an English eduction in Okinawa and the United States. Even though the program has other DJs who are on Tuesday and Thursday, I did not include them because they rarely use dialect, speaking almost exclusively English and Japanese.

The Director of the Program. The person who was in charge of the program was interviewed. He is in his $40^{\prime} \mathrm{s}$ and has been directing the show for roughly five years.

Interview with Ken, Masumi, and the Director. One interview with Ken, Masumi, and the program director was held at FM Okinawa after acquiring their consent (see Appendix A, Informed Consent 1). During the last phase of the overall study, after revealing the true purpose of my research for the first time, I conducted open-ended interviews with both 
disc jockeys, Ken and Masumi. Since most of the time code switching is considered to occur out of conscious awareness, it may not be appropriate to ask switchers to provide easy and rapid responses (Gumperz, 1982). In order to produce maximum freedom of their responses, the broader, more flexible interviewing method provided by qualitative techniques seems to be most appropriate (McCracken, 1988). I asked general to specific information about their language use and personal backgrounds, how and why code switching started in this program, how they viewed the program, what makes the program successful, what audiences' responses are, and so forth.

For their time convenience, I interviewed the program director together with Ken and Masumi. He provided his own view of the program, its success, and DJs' language behaviors as well as technical information about the program. The interview with these three took thirty minutes and was recorded for transcription.

Listeners. Unlike most mass media studies which rely on quantitative methods can be seen (Lindlof, 1991), I did not select random samples from the audience population. Instead, I went to the FM Okinawa and the Book Box station where I could observe those listeners who were potential interviewees for my investigation. In this program, these DJs encourage listeners to visit their show. The number and quality of interviewees was shaped by those interested listeners who 
went to these stations to actually see the DJs.

Interviews with Listeners. Data from listeners provided

a basis of analysis for what they thought about the program.

I applied the funnel format for the interview construction,

"in which broad open questions are used to introduce the questionnaire or interview, followed by narrower closed questions that seek more specific information" (Frey, Botan, Friedman, \& Kreps, 1991, p. 111). The questions addressed such issues as what did they think of the program; what program features did they like or dislike; what did they think of the DJs' way of speaking; and how aware were they of their own language behavior regarding code switching.

These questions were designed to reveal some of the issues presented in the initial research questions (see p. 5) such as naming the effects of the DJs' tri-code speech style on natives, the natives' perception of the DJs' language usage, and the natives' perception of their own language usage. First I asked general questions about the program and the DJs' speech style, and then I went on to more specific questions about interviewees' own language behaviors. It seemed to be appropriate and effective in helping the interviewees to understand these questions as well as their themes. The funnel format also avoided biasing the interviewees' answers, "by allowing them to describe first their behavior, knowledge, and attitudes regarding the overall topic before a researcher asks more directive 
questions" (Frey, Botan, Friedman, \& Kreps, 1991, p. 111).

Short informal interviewing took place at the studio of FM Okinawa and the Book Box satellite station where potential interviewees dropped in. I interviewed fifty-one people (19 males and 32 females). Their ages ranged from low teens to early 20 's. Each interview took about three to five minutes after obtaining their consent (see Appendix A, Informed Consent 2).

Interviewing young people was occasionally difficult in drawing their spontaneous and free feedback. I approached them in a casual manner and asked them to participate in this study. They did not refuse to give interviews yet they tended to be reserved when approached by an unknown person in a public place. Some of them, especially the junior high school girls, hesitated and did not answer some of the questions but remained silent. I had no intention of controlling their responses. Therefore, I had to skip a question and go on to the next. Most of them also refused to have their interviews recorded, so, I employed a note taking procedure to record their responses.

Possible reasons for this difficulty might be explained by the general cultural environment in which these encounters occurred. Contrary to the American spoken society where oral performance is an important skill for individuals to acquire, there is a prevailing value of silence in the Asian culture (Gudykunst \& Ting-Toomey, 1988) which includes Okinawa as 
part of Japan. In such a cultural context, verbal expressiveness is not highly valued in interpersonal communication (Okabe, 1983). Furthermore, the nationwide opinion poll interview conducted by NHK (Nippon Hoso Kyokai, Japan Broadcast Institution) in 1978 found that the Okinawan people showed the poorest verbal responses to the investigators of the poll (Agarie, 1983). Agarie (1983) points out that Okinawans tend to cut themselves off from strangers and have clear distinctions between ingroup and outgroup members. More effective interviewing skills in dealing with this group of people need to be devised. Despite this difficulty in the interviewing process, data were collected on the listeners' major opinions of the program, the DJs' way of speaking, and of their own language behaviors. Some of the interviewees were awkward with an unknown investigator. But my ethnic status as a native Okinawan, who acknowledges local culture, language, and native behaviors, made me more communicatively competent than a non-native researcher. This advantage probably helped me in obtaining data from the okinawan listeners.

The Older Locals. Since "Pop'n Roll Station" is a musical program which broadcasts mainly American and some Japanese contemporary rock and popular music, listeners ages range roughly from low teens to the late 20 's. In order to compare the different age groups' perspectives, interviewees were selected from the older locals who at least know about 
this program and have some knowledge about the DJs' way of speaking.

I employed a nonrandom convenient sampling and the snowball technique in order to select subjects (Frey, Botan, Friedman, \& Kreps, 1990). Some of the locals were selected nonrandomly simply because they were available (convenience sample). Then I asked them to refer to other people who might be able to serve as interviewees (snowball technique).

Interviews with Older Locals. Fifteen older locals (4 males and 11 females) participated in the interviews. Their ages ranged from early 40 's to late 60 's. Interviews took about ten to twenty minutes at their houses and workplaces after acquiring their consent (see Appendix B, Informed Consent 2). Recording interviews sometimes was not welcome here either, forcing me to take notes. However, I did not find the same problem that I had with the young listeners during the interviewing process since all of these older people were familiar with me, and therefore, were more outspoken than the young listeners. 


\section{CHAPTER V}

\section{ANALYSIS OF DATA}

This chapter begins with interview data from listeners, older locals, the program disc jockeys, and the program director. The latter section presents analysis of the DJs' code switching.

\section{INTERVIEW RESULTS}

\section{Interviews with Listeners}

I asked five questions of fifty-one program fans whose ages ranged from low teen to early 20's: (1) what do you think of the program; (2) what do you like or dislike about the program; (3) what do you think of the DJs' way of speaking; (4) do you use Japanese and dialect in the same way as the DJs do; (5) if you do, when, where, and with whom do you do so.

In answering the first question, over half of the program fans indicated that they think Pop'n Roll Station was interesting. When asked, those listeners said: "I think it's interesting," "they play my favorite music," "I like it," "it's fun," "I listen to it often," "I think it's interesting, for example, the DJs' conversations," and "I like the DJs." These were the most common response to the 
first question. Yet some people had trouble answering the first question either remained silent or remarked "What do I think of it? Well...nothing."

To the second question, those listeners of the program who took the trouble to come to FM Okinawa and the satellite station at the Book Box said that they like the show for its good sound quality (Okinawa has only two FM stations), music, the DJs, the DJs' conversations, and the DJs' way of speaking. Most of them particularly showed their favorable comments about the DJs. Their general responses to the DJs are: "they are a good pair," "their conversations go fast and don't bore me," "the DJs are friendly," "their conversations are interesting, they talk about familiar things," and "they are fun." Listeners did not identify program features that they did not like.

The third question led to listeners' perspectives toward the DJs' language usage. Most of the listeners said that they like the DJs' speech style: "I enjoy it," "it's interesting," "that's very good," and "I like this mixing things [languages] up" were common responses to the question. Actually most of the listeners' comments about the DJs' dialect usage were spontaneously offered in the course of the interview. Those who referred to the DJs dialect said "I enjoy their dialect," "I enjoy it because I can hear dialect that we often use in school," "I use dialect so, sometimes, they could teach me some new dialect," "they speak something 
like us, mixing dialect into Japanese, you know" and "their dialect makes me feel close to them." Several listeners also spontaneously referred to the DJs' English and said "their English doesn't bother me a bit even though I don't understand it," "I like their way of using languages, even though I don't understand their English, they give [Japanese] follow ups," "I admire their English," and "listening to their English could be good [English] practice."

While respondents may have had difficulty with the DJs' English, to the fourth question, all of listeners said that they understand the dialect spoken by these DJs. For example, a female office worker said "I understand the dialect that is used in this program." Her friend agreed by saying: "yeah, me too." However, nine of the listeners responded that they cannot use dialect while the rest of them said that they are able to use it but only partially. Roughly half of those who said that they use dialect considered the DJs' dialect usage to be the same as theirs. The common responses to this issue were: "they [the DJs] speak like us," "I use dialect like them," "I understand their dialect because I use it like they do," "Dialect I can use is like that [referring to the DJs' dialect]."

When asked when, where, and with whom they use dialect, listeners answered: "with my parents and my friends, I use dialect often," "I use dialect with my friends," "I use dialect, not much though, I don't use it to my boss, but [I 
do] to my friends," "at school, I use dialect with my friends," "I don't use it much but I understand it," "I know the commonly used dialect, I don't know all dialect though," "I use dialect when I get mad," and " I used dialect, it's not the real one though." Their responses revealed that dialect is used when they are among friends, with families, and at school.

\section{Interviews with Older Locals}

I basically asked the same questions to fifteen older Okinawan residents whose ages ranged from early 40 's to late 60 's. They clarified their attitudes toward the DJs' way of speaking. Their interest in the language usage by the DJs were primarily related to the issues of dialect.

When asked what they thought of the show, most of residents interviewed responded that they do not have special opinions about the show as it is a "young people's show" and since they do not regularly listen to it.

I don't know about the show, because it's a young people's show.

When I'm home from work [in the car] I often overhear it, lots of music, kinds of music that kids like. That's all I know [about the show].

There were two locals who clearly did not like the show. They said:

I sometimes overhear the show when I'm in the car, but it makes me irritated and I change the station. I don't like it. They [DJs] sound stupid, [DJs] say stupid things. 
They are radio spokespersons. They have to use appropriate language on the air. They talk too casually.

Since most of them said that they don't listen to the show regularly, the second question turned out to be not as suitable for those older people. However the two locals who did not like the show repeated that they did not like the DJs' conversations and language style either.

To the third question, what do you think of the DJs' way of speaking, the older interviewees did have various opinions :

I guess young people like it [the DJs' way of speaking]. It's kind of a strange way to talk. Kids might like it.

In Okinawa, that kind of speaking might be accepted.

I don't like it. They are bragging that they can speak three languages.

That kind of speaking is actually not rare. I used to have a mixed-background friend who talked like that.

It's good to be able to speak English, Japanese, and dialect.

Beyond these general comments on the DJs' way of speaking, older locals' attention seemed most often drawn to the issue of the DJs' use of dialect. Some of the older locals viewed the DJ' dialect as representative of the young people's way of using it:

That's [the DJs' way of using dialect] the current generation's way, I guess.

Some kids talk like that. Some can't use dialect at all though. 
Sounds strange but that's [the DJs' way of using dialect] the way they [young people] talk.

Unlike the consistently favorable comments made by the program fans, older informants said:

I don't like the dialect that young people [including the DJs] use now. It doesn't have class. It's not the real dialect. The young generation who can't understand dialect is increasing. If you speak dialect, you should learn proper dialect.

I feel like if you use dialect, you should use it in a proper way...their [young entertainers including the DJs who use dialect] dialect doesn't sound right.

Young people talk like that [referring the DJs' dialect], when they use dialect. Sounds kind of the dialect, but not the real one, but that's dialect for them.

I think you would rather speak standard Japanese instead of using such strange dialect.

It's [the DJs' dialect] broken.

These older people considered the commonly used dialect by the young people to be "broken" which means a bastardized version of the okinawa dialect. In their responses, these older residents actually answered the second question. One program feature that they did not like is the DJs' way of using of dialect.

In contrast to the criticism of the DJs' dialect usage in the popular radio program, supportive comments were also heard from older locals:

I guess it's OK because it's kind of interesting. It's good [DJs' dialect] I think. Before this type of people came in, dialect was really declining. It's good to keep some of the interesting dialect even if it's not pure dialect. I encourage that. 
Language changes. No one can stop it. There are languages for each generation. For the young generation, that's this way of speaking dialect, might be called more appropriately OkinawanJapanese though.

Someday, [pure] dialect might vanish but it's good to keep this kind of dialect [referring to young people's dialect usage] isn't it? Dialect will be preserved as a product of the present day by incorporating things at this time.

In the past, when Okinawans were discriminated against by Japanese, to speak dialect was a shameful thing. But now, those people [young people including the DJs] start speaking okinawan-Japanese openly. That's a good thing.

Although older informants paid more attention to issues of dialect and spent more time discussing them, they did express positive attitudes for English as well in the interviews:

Now, lots of people learn English. Studying English is popular now.

Being able to speak English is good.

Many people go to America to study English these days. I wish I could speak English.

It's good, to speak English and Japanese and dialect, mixing them all up. Times have changed, people's evaluation of English has changed. So it's good to be able to speak English.

The number of the mixed-background people is increasing, because Okinawa has the bases. We're gonna have more bilinguals. To be able to speak English is a good thing.

I asked them "Do you use dialect and Japanese like these DJs?" All of the older locals offered negative responses to the fourth question. Therefore, the fifth question was not asked to those people. Several general answers are listed as 
following:

I don't think so.

No, I don't. I don't use dialect like that.

Do I? No, that's young people's way [of using

dialect]. Old people don't talk like that.

old people use real dialect.

I don't use much of dialect any more. I speak Japanese mostly.

\section{Interview with Ken and Masumi}

The questions addressed to these DJs dealt with such issues as how their language usage started in the show; what listeners' responses are to their way of speaking; what makes the show successful; and the reasons for using their "trilingual" speech style.

Both DJs explained that they had no intention of using dialect on purpose when they started the show but it naturally came out because they use these languages everyday. Ken said:

We [the DJs] didn't have any thoughts like we were going to use dialect in this show... So, it's natural, because we use it everyday. For example, "AHH!(Oh) DEEJI! ("I can't believe it" in dialect) man."

The DJs continued:

M: all mixed-background speak something like that.

$\mathrm{K}$ : not everybody.

M: oh, not everybody.

When I asked if there are individual differences in using the three languages, Masumi answered there are. Yet Ken said 
they use three languages if their conversation partners are "mixed-background." Masumi explained that she selects languages depending on conversation partners:

So, when we go to drink with our colleagues, it becomes like that [referring to their usage of three languages] when Ken and Masumi talk... and [I] keep talking like that with the director, and I realize oh, he is a Japanese, so I stop [using English].

Thus, from Ken and Masumi's perspective, regular use of English, Japanese, and dialect on the show was not artificially created for the program but emanated out of their everyday use of three codes. Ken and Masumi also said that they do not consciously choose languages depending on conversation topics and do not have scripts of the show:

M: we improvise things to say... if Ken says something I say something back to him.

$K$ : it's natural.

In addition to their view of the natural emergence of dialect in their conversations, the DJs offered several other reasons for using dialect in the program:

Our show is, well, a request program. People who are listening to us are mostly Okinawans. So, speaking dialect in a casual manner makes

listeners feel comfortable, I guess.

At the time we had just started, we were told not to use much dialect. But people who are listening to us are Okinawans. So if we speak only standard Japanese and English, it' 11 be the same as other FM [bilingual DJs] right? If we want to express the real okinawa, only dialect can do that.

There are certain things that can be expressed only in dialect. For example, saying DEEJI ("I can't believe it" in dialect) is more intense than TAIHEN ("I can't believe it" in Japanese). 
Ken also encouraged using dialect:

Language is communication. If Okinawan blood runs in your veins, I think you should know your language [dialect].

I know I make mistakes in my Japanese and dialect. Mine is sometimes a kind of dialect. But it's OK to make mistakes. So just use your language...I really think so.

Both said that they receive positive responses from

listeners about their language usage. Ken expressed:

One of the listeners said [she/he] is getting used to Ken and Masumi's way of speaking, and is gradually become good at English and able to understand dialect too.

Besides young peoples' responses, the DJs said that they also have received some of the older Okinawans' responses to their show. Ken expressed that messages from older people particularly flatter him:

Well, uhm, we have received cards from older people. At such moments I am moved because those are the people who speak real dialect.

Masumi also explained another reason why she feels moved when older people accept their English, Japanese, and dialect speech style:

I was moved when this person in his $60^{\prime} \mathrm{s}$ something sent us a card. He said when he was young, he used to work for the base and had many American friends. But time has changed a lot since then. He said when he listens to this show, it reminds him of his youth.

When asked what makes the show successful, both DJs said that is due to FM Okinawa:

$K$ : that's thanks to FM, FM Okinawa [laugh]

M: that's thanks to the director [laugh] 
Masumi also said that their success is because "it [the show] happened in Okinawa," where the mixed-background "can speak English, can speak Japanese, and can speak the Okinawa dialect casually" in their everyday life.

\section{Interview with the Director}

The director provided me with his view of the program and what he thinks makes the show successful as well as technical information about the show. According to the director, Pop'n Roll station is a show targeted at young people who like American music. He said that initially the station did not expect the show to be a big hit. He explained that one reason for its success is the DJs' way of speaking:

The reason why the show is successful is that, I think, these two's [the DJs] way of speaking.

He particularly emphasized the DJs' dialect as a success factor:

Actually, their dialect is not proper, words that they use are...they [DJs] use dialect in the way young people do, so, it's what kids like. Because they [DJs] speak in the way most of us do, listeners enjoy it.

He said that the DJs' use of dialect in the show have made "walls between the DJs and listeners vanish."

In terms of the DJs' English usage, the director said that the program aims to produce a certain effect by requiring the DJs to speak English. When asked why the DJs use English at the opening of the show, ending of the show, 
and introduction of music, the director explained:

At the program planning stage, we tried to make the show popular by requiring the DJs to use English and Japanese and playing American music. Generally, kids think English is cool...the show is for young people who like American popular music. If they like it, they might like English too. English is one of accessories to attract them.

His responses revealed that speaking English in the show is not always the DJs' spontaneous speech act but at least on these three occasions it was planned by the station from the beginning.

\section{SUMMARY OF INTERVIEW RESULTS}

Roughly half of the young listeners whom I interviewed accept the DJs' dialect as theirs. This is reflected in such comments as "I use dialect like they [the DJs] do," "I understand their dialect because I use it like they do," "their dialect makes me feel close to them," "they speak something like us," and "I enjoy it [dialect] because I can hear dialect that we often use in school." Their responses revealed that dialect is commonly spoken among friends, in families, and at school. From the program listeners' point of view, dialect used in close relationships creates and enhances a sense of belonging. Some of the older locals considered that the DJs' way of using dialect is the same as the young people's. "Young people talk like that [referring to the DJs' dialect]," "some kids talk like that," "that's [the DJs' dialect] current generations' dialect." These 
interview results suggest that the DJs and listeners seem to have created a bond in sharing the same way of using dialect and this has contributed to the program's success. It also implies that Ken and Masumi's dialect usage reflects how dialect is currently spoken among the young Okinawans.

However, older Okinawan residents had two contrasting opinions on the DJs' way of using dialect. Some of them consider the DJs' dialect including young people's to be too "broken" and reject it. Others encouraged young people to use this altered dialect. Considering the possibility of dialect extinction, the latter type of older Okinawans hope that young people will maintain part of the Okinawa dialect, even though it is in a different form from the original. The interview with the director revealed that FM Okinawa uses Ken and Masumi's speaking English as one strategy of attracting young people who are generally believed to have an English preference. Consistent with the station's expectation, some of the listeners displayed their preference for the DJs English. In terms of English, older people showed generally positive attitudes. The interview data support an assumption that it is prestigious to be able to speak English in contemporary Okinawan society.

Ken and Masumi's speech style has recently gained public attention. However, one older local's reference to his mixed-background friend who spoke like the DJs and the DJs' own comments about other trilingual mixed-background 
speakers suggest that English, Japanese, and the Okinawa dialect code switching has existed in Okinawan society as one way of speaking for sometime among a small number of racially mixed people. Masumi explained their success related to the Okinawan social situation. In a sense, the DJs' speech style reflects the historical development of okinawa with the U.S. bases because three language contact was a result of the intercultural encounters between Okinawans and Americans.

\section{DESCRIPTION OF THE RESEARCH FIELD}

This section presents the general context in which the radio program is broadcast and the program as the specific speech situation.

\section{Speech Communities in Okinawa}

As a whole context in which code switching behaviors under investigation take place, speech communities in okinawa need to be introduced.

The Okinawan Speech Community: The Current Situation. Okinawan history has created a distinctive locality and strong identity among Okinawans. According to the Nippon Hoso Kyokai (NHK, Japan Broadcast Institution), the Okinawans scored the strongest on degree of locality among Japanese in the 1978 nationwide opinion poll. Their dialect differentiates between the local people and the mainland Japanese: uchinanchu and yamatonchu. Many regions in Japan 
have local dialects, but there is no other region that has a dialect which differentiates local people and the rest of the Japanese (Okinawa Chiiki Kagaku Kenkyujo [Okinawa Regional Science Research Center], 1982).

However, this Okinawan identity seems to be experiencing a transformation. Kato (1985) contends that as the unification of Okinawa with Japan develops, Okinawan culture is more assimilated into Japanese culture and local peculiarities are vanishing. Agarie (1991) states that the language transition has played a major role in promoting this cultural assimilation. A short column written by an Okinawan writer (Kadena, 1988) describes the identity transformation among young people:

"Agaa." Dialect uttered when you feel pain.....As long as you are an Okinawan, you utter this word. But the recent young generation who don't say "Agaa" is increasing.... Those are the people who were born after about 1970. They say "Itai!" (Ouch in Japanese) instead of "Agaa." That reminds me of when I asked a girl who was born in 1978, "you don't understand dialect?" Then she said, "nope, because we are Japanese since we were born." Inside of me, unconsciously, I said "Agaa" (p. 19-20).

As this story tells, the younger the generation is, the less dialect is spoken and the more identity transformation is taking place.

Agarie (1991) categorizes Okinawans into four types: Japanese-wanna-be, marginal-Japanese, assimilated-Japanese, and negative-Japanese. He suggests that the majority of the Okinawans now probably considered to be of the third type. Under this condition of Okinawan society, people have 
begun to realize that their identity has been in the transition process from Okinawans to assimilated-Japanese. While this process is gradually developing throughout Okinawa, a phenomenon which a local scholar calls is "cultural nostalgia" (Komesu, 1991, p. 32) has appeared as if it were a resistance to this transition. The okinawans have recently started reevaluating their local culture, particularly focusing on Okinawan dialects as a response to their near extinction. Inviting old okinawans as lecturers, dialect workshops are held in cities and towns. A theatrical group presented a play entitled "So Long, Okinawan Dialect" and expressed the current social condition of the dialect extinction in Okinawa with humor and satire. A new type of young okinawan comedians who intentionally use dialect including Okinawan-Japanese have appeared on TV creating a new way of expressing "Okinawaness" in their language performances.

The American Speech Community. Besides the Okinawan speech community, there is another distinctive group of people in Okinawa: the American English speaking community which occupies twenty percent of the island with the Marines, Navy, Army, and Air Force units. Its numbers are reported 30, 435 military personnel (Marine, 19,225, Navy, 2, 327, Army, 869, Air Force, 7,984), 902 civilian employees, and 21,012 of their dependents. These two communities are mutually exclusive in terms of languages spoken in each. 
The Mixed-Background People in Okinawa. The intercultural encounters between Americans and Okinawans have produced the racially mixed people who belong to the above two speech communities, although the number of this group of people is not clear and is supposedly small. Individuals of mixed-background attend international schools in Okinawa. Acquiring mostly an English education, they are raised as Japanese-English bilinguals. Neither their social identities nor linguistic variations have yet been fully investigated. The main research subjects, Ken and Masumi belong to this group of people. At the same time, they are considered to be two of the Okinawan entertainers who speak dialect to express their Okinawan identity in their language performance. This situation provides a context for the study of a trilingual code switching.

\section{The Research Field}

FM Okinawa and Pop'n Roll Station. FM Okinawa, which was formerly an AM radio station called Kyokuto Hoso (Far East Broadcasting), was originally founded by an American Christian organization in 1952 . With the reversion to Japan in 1972, the station was approved as a Japanese commercial broadcasting company. The station started FM broadcasting in 1984, changing its name to FM Okinawa, and is now one of the six radio stations currently operating in Okinawa. FM Okinawa's unique characteristic is its employment of 
Japanese-English bilinguals as DJs. The target ages of the audience are low teen to the 30 's, and at most the 40 's. "Pop'n Roll Station" is one of its regular weeknight programs which plays mostly American rock music and some Japanese popular music. The average rating of the program is around twenty percent which is quite high in Okinawan radio competition.

The main subjects of this study are two DJs, or radio hosts, who speak Japanese, English, and the Okinawa dialect in this program. These "trilingual" DJs, Ken and Masumi, are Okinawan-born-Japanese-Americans who acquired an English education in Okinawa and the United States. Hired for Pop'n Roll Station in 1986, they are the only ones who speak dialect among all bilingual DJs. Ken and Masumi are on the air six hours a week from 7 p.m. to 9 p.m. on Monday, Wednesday, and Friday. The program is broadcast on location Friday evenings at the Book Box store at Makiminato, Naha. Program listeners are regularly invited to drop in to see Ken and Masumi while the show is being broadcasted from the Book Box satellite station and the studio of FM Okinawa.

Speech Situation/Structure of Pop'n Roll Station. The program is divided two sections; part one $(7 \mathrm{p} . \mathrm{m}$. to 8 p.m.) and part two ( 8 p.m. to 9 p.m.). The DJs play mostly American rock and some Japanese popular music requested by listeners via telephone, facsimile, postcard, and letter. While requesting music, listeners send the DJs messages about 
events in their personal lives. The DJs start the show in English. After a commercial break, part one begins. In part one of the show, the DJs greet the listeners, have short dialogue about themselves, present routine information, read from those postcards or letters, respond to these listeners' messages with their comments, introduce in English music requested, and play music. About seven messages and songs are read and played during part one. Three commercials breaks take place between the DJs' interaction with listeners and music.

At the beginning of part one of each program, the DJs inform listeners what the theme is for part two and ask them to send their responses on this particular issue by telephone or facsimile during the first hour. When the show does not have a special theme for part two, which occasionally occurs, the DJs ask listeners for various kinds of stories with requests for music. One of the staff members of the station takes care of incoming faxs and phone calls, dictating and summarizing messages so that the DJs can read from them during part two of the show.

After repeating routine information, the DJs begin part two with their dialogue about the evening's theme or discuss various topics unless they have evening's theme. They read from the listeners responses, introduce in English music requested, and play music. About eight messages and songs are read and played. Three commercial breaks take place 
between the DJs' interaction with listeners and music. The end of part two is the end of the program; it is closed by the DJs' remarks in English.

The program also provides special announcements such as concerts, festivals, items of lost and found, and donations. Announcements are read at various times between listeners' messages. Figure 3 illustrates the basic structure of the two hour show.

A. Opening of the show (approx. $1 \mathrm{~min}$.) general introduction in English/phone and fax number information (commercial break)

B. Part 1 (1st hour): Introduction (approx. $2 \mathrm{~min}$.) greeting by the DJs/short dialogue between the DJs (topics vary) presenting theme for part two, phone/fax numbers given asking for listeners' participation Interaction between the DJs and listeners (approx. $2 \mathrm{~min}$.) introducing, reading from, and commenting on listeners' messages Introducing music in English Playing music (approx. $3 \mathrm{~min}$.) Conclusion, part 1 (approx. $1 \mathrm{~min}$.) asking for listeners' participation/announcing the address of FM Okinawa asking listeners to stay turned for part two (commercial break)

C. Part 2 (2nd hour): Introduction (approx. $1 \mathrm{~min}$ ) evening's theme, phone \& fax numbers given/ask for listeners' participation (commercial break)

DJs discuss the evening's theme (approx. 2 min.)

Interaction between the DJs and listencrs (approx. 2 min.) introducing, reading from, and commenting on listeners' messages Introducing music in English

Playing music (approx. 3 min.)

D. Conclusion, part 2 and the program (approx. $2 \mathrm{~min}$.) thanking listeners who participated/asking for listeners' next participation announcing the address of FM Okinawa/closing the show in English

Figure 3. Structure of Pop'n Roll Station.

In addition to the general structure explained above, the program has additional events for each show. These 
events usually take place at the end of part one. The following examples are of those additional events.

Monday: Haisai Shimanchu Communication (Hello Okinawans Communication)

The program picks up one of the listeners and makes a call in order to let DJs have a conversation with this selected person.

Wednesday: Ken and Masumi's DJ Power Pick

The DJs provide musical information and select one special song to play for the listeners.

Friday: Pop'n Roll Birthday Corner

The DJs introduce messages from people whose birthdays are coming up or friends' messages to those having a birthday.

The DJs often code switch during different speech events in this speech situation. Their code switching activities are governed by norms and rules for the use of speech. The next step is to discover these norms and rules.

$$
\text { ANALYSIS OF "POP'N ROLL STATION" }
$$

As mentioned earlier, studies of code switching take either a linguistic or social orientation approach. My perspective in this study is the latter one. While inclusion of certain linguistic features is necessary for an analysis of the code switching phenomenon being studied, a detailed analysis of grammatical features of code switching is not included since my focus is the context and social factors in which code switching occurs.

I employ Hymes' descriptive-theoretical framework (1986) in this study of code switching. A descriptive framework 
provides for the analysis of communities "by specifying technical concepts required for such analysis, and by characterizing the forms that analysis should take" (Hymes, 1986, p. 53). Sherzer and Darnell (1986) suggest that finding the components involved in the use of speech is the first analytical step that an ethnographer takes. Hymes' SPEAKING formula is applyed to discover the potential components in code switching activities. The presence of a rule or structured relation of code switching can be found in the shifts among those components (Hymes, 1986).

The first procedure in this analysis begins with analysis of the program "Pop'n Roll Station" as a speech situation utilizing the components of Hymes' SPEAKING mnemonic. This provides a thick description (Geertz, 1972) of the situation in which the variety of code switching activities under investigation take place. Then I conducted a micro-level analysis of the selected samples of DJs' verbal interactions from transcriptions in order to discover the patterns of the language choices based on the code switching structures and functions.

\section{Analysis of Mnemonic SPEAKING: Pop'n Roll station}

Setting: From the standpoint of a general description, the setting in this study is the radio program "Pop'n Roll Station." It is also the speech situation which comprises various types of events associated with the DJs' speech. 
The program is broadcast from the studio of FM Okinawa on Mondays and Wednesdays and the Book Box satellite station on Fridays. The Book Box is a bookstore and video rental shop; its character makes it a place where people drop in, especially at night. On the second floor of the store, there is a small radio station where occasional broadcasting of FM Okinawa takes place. It is here that customers can see Ken and Masumi through the glass enclosure on Friday evenings.

Scene: Pop'n Roll station is a radio program which is especially designed to provide American rock and Japanese popular music with the DJs' light-hearted entertaining conversation for a young audience. The show provides those youngsters a chance to discuss the events happening in their lives with the DJs. The local topics that the DJs talk about and their dialect create a relaxed, familiar atmosphere. American music played during the program and English spoken by the DJs also helps to create an Americanized atmosphere on the show.

Participants: Ken and Masumi play multiple roles while participating in the show. They are speakers and addressers to the program listeners as well as they are hearers and receivers taking turn in their own conversations and receiving listeners' messages addressed to them. Okinawan listeners are divided into two types: the message senders who participate in the program and the general audience. Message 
senders get in touch with the DJs by postcards, letters, telephone, and facsimile. The general audience category can be further divided into two types. The first consists of those listeners who come to FM Okinawa and the Book Box satellite station and the second is those who listen the show elsewhere. Since the DJs mention the American audience when speaking English, they seem to include the Americans as part of their program listeners. However, it is difficult to determine how much the Americans listen to the show because the show does not receive many responses from Americans. Only one message from an American boy was heard during the three-month observation period. None of the American listeners came to FM Okinawa and Book Box, expect some American friends of the DJs'. All of the listeners who came to FM Okinawa and the Book Box satellite station during my observation were young Okinawans.

Ends: Analysis reveals that the show has distinct but related goals. One is oriented by the commercialism of FM Okinawa and the other is the DJs' personal contributions in serving the local community as local entertainers.

The show provides popular American music to the young people; employment of the English speaking DJs is one of station's commercial strategies to attract the young audience who like American music. On three specific occasions during the program, the DJs speak English as the program requires them to do. Pop'n Roll Station is a request program. The 
DJs encourage listeners to participate in the show, to request of music, and to send in personal messages while entertaining the audience with their light-hearted conversations.

The DJs often talk about various local topics and the importance of the local culture in dialect so that they can express Okinawan identity and share it with the program listeners. These mixed-background DJs use English to address the American listeners and ask for their participation in the show as if they were trying to mediate two different language speaking communities.

Consequences of these goals are manifested in the show's big success and Ken and Masumi's publicity as the mixedbackground "trilingual" DJs.

Act Sequence/Message Form: The DJs employ informal and formal language style.

In their conversation, when the informal Japanese speech form is used, the use of direct verb predicates predominates. When the formal style is used, the use of distal verb predicates predominates. According to Jorden and Noda (1987), these two predicates of verbs mark participants' relationships. While direct predicates are used in informal and close relationships, the use of distal predicates reflects a degree of formality with a certain distance among participants. The informal style also contains more fragments, contracted forms, shorter and simpler sentences, 
and the kinds of sentence particles which mark it as colloquial, assertive, brusque, coarse, and confirmatory. On the other hand, the formal style is defined by the less frequent use of such forms and particles (Jorden \& Noda, 1987) .

In terms of English, the informal style contains shorter and simpler sentences, fragments, contractions, colloquial expressions, and slang while the formal style uses longer and more complicated sentences as well as a less frequent use of fragments, contractions, colloquial expressions, and slang.

Okinawan dialect interjections, phrases, and short sentences were always in the informal style. Since dialect is only used in informal close relationships, it brings a casual flavor into the conversations. The formal style of dialect was not heard during the observations, nor found in detailed analysis of the transcriptions.

The DJs predominantly use the informal style in the show. In order to express the different degrees of informality found in their informal style, I use the terms maximum and minimum in this analysis. Their conversations shifted between maximum informal, minimum informal, and formal style. The maximum informal style is used when the DJs talk about themselves; the minimum informal style, which contains some formal style features is employed in most of the program routines and statements addressed to the listeners; and the formal style is heard in some of the 
prepared special announcements which deal with serious matters such as donations for needy people.

Act Sequence/Content: The topics of the DJs' conversations vary as well as the issues that listeners bring to the show. Both the DJs and listeners discuss specific features of their personal lives such as school, work, friends, love life, families, etc. The DJs often discuss local topics such as Okinawan traditional dances, Okinawan folk music, Okinawan summer vegetables, and the importance of local culture. Although the DJs often mention the events happening in the American military bases, they do not talk about conflicts between the local people and the American bases, indicating their sensitive social status as mixedbackground people. Issues of special announcements heard during the three-month observation period included concerts, festivals, donations, and lost items.

Key: The tone of the program overall is essentially light-hearted. Unless the issues being discussed require a certain degree of seriousness, the DJs keep to their cheerful conversations, constantly telling jokes and funny stories. The DJs' interactions with the listeners are carried on in a friendly and familiar manner as the listeners bring personal issues to discuss. The DJs laugh a lot and often produce paralinguistic sounds such as raising intonations, blowing a whistle, and giving a shout. They also occasionally 
intentionally speak with strong Okinawan accents in their Japanese.

Instrumentalities/Channel: The DJs' audio oral interactions take place in a radio program. It is also visual since listeners who visit FM Okinawa and the Book Box satellite station can see the DJs' interaction though the glass enclosure. Listeners who participate in the show contact with the DJs through postcard, letter, telephone, and facsimile.

Instrumentalities/Form of Speech: Reflecting linguistic variations in the Okinawan speech community, the DJs' conversations are mostly in Japanese. Roughly 65 percent of the DJs' discourse is in Japanese, 25 percent in English, and 10 percent in dialect. The proportions for these codes given here are based on a word count of transcriptions. These percentages are approximate as it is difficult to compare these grammatically different languages since in contrast with English, Japanese and Okinawan dialect do not have a writing system which separates each word grammatically. These numbers are presented as rough estimates only.

Norms of Interaction and Interpretation: There are three kinds of norms governing the DJs speech activities in this show. The first one is imposed on the DJs by the structure and purpose of the radio program. Since "Pop'n Roll Station" is a live radio program, the DJs are obliged to keep 
constantly talking and should not be silent. Under this norm which plays a major role in creating the show, the DJs' speech can be divided into two categories. One is planned and routine; the other is improvised and spontaneous. In these conversations, how they speak and how they choose a certain code reflect general sociolinguistic values and norms in the Okinawan speech community where the show takes place. Being part of youngsters' popular culture, the DJs' speech style are also governed a specific language norms and values in the younger generation which is a subgroup within the Okinawan speech community.

Genres: Genres discovered in the program include: music, song, information, jokes or joking, mocking, narratives, announcements, questions and answers, advice, gossip, and the commercials.

\section{ANALYSIS OF CODE SWITCHING}

This section presents the analysis of the DJs' code switching behaviors with specific examples offered to illustrate the DJs' code switching.

\section{Structures and Functions of the Code Switching}

Since Pop'n Roll Station is a radio program which has a schedule to follow, the DJs' discourse can be divided into their scheduled conversations which are heard in each show and their spontaneous conversations which result from 
listeners' input or dialogue between the DJs. The following section discusses the DJs' code choices found in these two kinds of conversations in terms of the structure of code switching: situational and metaphorical.

\section{Situational Code Switching}

According to Blom and Gumperz (1986), situational code switching relates to a relationship between language and the social situation. Participants change their language based on the definition of communication situations. For instance, one language is spoken in a certain situation; the other is used in a different situation. In this program, situational code switching occurred based on the DJs' obligation to fulfill the duties of their program routines which require certain codes to be used.

The program has clear schedules which the DJs are obliged to follow in every show. As the show continues according to these routines, different speech events occur in the DJs' discourse. The director said that these routines do not reflect the DJs' spontaneous speech acts but are programmed from the beginning by the station. In these routine discourse, the DJs' English and Japanese situational code switching are both discovered.

\section{English Situational Code Switching}

According to the director, it is the DJs' obligation to open the show, end the show, and introduce music in English 
in order to attract young listeners who like American music and English. The next two examples illustrate the DJs' English situational code switching required by the station.

Example 1. 8/19/91

A program routine performed in English The opening of the show:

1. $\mathrm{K}$ : good evening everybody M: heey HAISAI UCHINANCHU (hello Okinawans)

2. $\mathrm{K}$ : how is your party action weekend warrior, hope things are going to flare up so that you all get it together and cruise though the rest of the week

3. $M:$ woo!

K: with party fever we got lots of great things in

4. K: store for you so stay in touch with this wavelength it's $87.3 \mathrm{FM}$ Okinawa

5. M: that's right Pop'n Rollers, lets just forget about all bad and terrible things that had happened in the past, look into the future for brighter thing we'll show you how, 'cause your DJs, crazy DJs, Ken and Masumi come your way, don't forget dial these magic numbers it's 872-2563 [in English] 877-2563 BAN [in Japanese] FAKUSHIMIRI 875-4566 [in Japanese] (fax number )

6. M: for Ken and Masumi's magic request machine K:

Okey Dokey

7. K: fans HAJIMAINDOO on Ken and Masumi's fabulous (let's get started)

8. K: Pop Pop'n Roll Station M: Pop Pop'n Roll Station woo Monday [echo]

Example 2. 8/19/91

Ken introduces music in English. After the music, Masumi repeats the title of the song and the name of the artist in English: 
1. K: OK, let's move on, it's your request we play it for you right here on Pop'n Roll Station, Randy M. C. with "Ghost Busters"

[MUSIC]

2. M: that was Randy M. C. with "Ghost Busters"

As noted earlier, the interview results seemed to suggest that both younger and older okinawans are positive about English usage. However, why do these Okinawans like the DJs' English? Reasons for this phenomenon could be explained by a larger cultural environment in which Okinawa is part of, that is, Japan's favoritism of English created by mass media.

English Favoritism in Japan. Although Japan is a monolingual country, its mass media extensively uses Western languages alongside Japanese to create, according to Haarmann (1986), impersonalized multilingualism as a channel of foreign influence to individual Japanese. Foreign words in magazines, newspapers, TV commercials, and popular music create stereotyped images of North America and Europe. Among these foreign languages, English is the most fashionable. Haarmann (1986) contends:

Anybody in Japan may tell you that it is fashionable to use English on different occasions and for different purposes, particularly among younger people, for whose speech behavior the language usage in the mass media sets basic standards (p. 212).

English has acquired higher prestige in contemporary Japanese society, especially by younger people. In addition to this 
media effect, there is the fact that English is the predominate foreign contact language for Japanese, thus encouraging many of citizens to learn this specific language (Pepper, 1990).

Haarmann (1986) states that English enjoys its high prestige given by Japanese people who have an English preference. Perhaps it is no surprise that the okinawan young people who have been exposed to Japanese mass media share the same attitudes. Since Okinawa is part of Japan, influences from the mainland cannot and should not be ignored.

The DJs' English in these three program routines resulted from the English favoritism and certain values attached to English by the Japanese mass media which has been creating fashionable images about Western languages, particularly English. The listeners' statements such as "I admire their English," "it's fun to listen to English," "I like it [the program], I can hear English in their [DJs '] conversations," "their English doesn't bother me a bit," and "listening to their English could be a good [English] practice" indicate those young okinawans' positive views of speaking English. In terms of the English preference, older okinawans gave the same responses. One of the older local interviewees in her $50^{\prime} \mathrm{s}$ said "now people's evaluation of English has changed, being able to speak English is a good thing." 
Within this specific English language preferred environment, speaking English in the program definitely creates a image of being fashionable which is one of the program's success factors in attracting young Okinawans.

\section{Japanese Situational Code Switching}

While the DJs' English is required in these routines by the station, the DJs' exclusively use Japanese during other routines to address the Okinawan listeners; dialect is rarely heard when they are performing these scheduled program routines.

Example 3. 7/3/91

A program routine performed in Japanese The DJs thank people who came to FM Okinawa and ask for listeners' participation:

1. M: KYOMO HAYAI JIKANKARA FMNI ASOBINI KITEKURETERU MINASAN DOOMO SANKYU, (today, as well, to those of you, who've come to FM okinawa \{studio\} from this early hours, thank you)

2. M: YUKKURI SHITETTE KUDASAINE

(make yourself comfortable, please)

K:

[

DOOZO DOOZO

(please, please)

3. M: DE ATOWANE, RAJIOWO KIITERU MINASANDE OHAGAKIWO ZEHI KAKITAIKEDO NANIWO KAITEIIKA WAKARANAI TTEYUKATA, SONNNA, NEE, FUKAKU KANGAEZUNI KIGARUNI KAITE KUDASAI (and, among the people who are listening to the radio, if there are anybody who wants to write us but don't know what to write, well, don't think deeply but write casually, please)

Example 4. 7/3/91

Masumi announces the theme for part 2 and provides phone and fax numbers : 
1. M: OMATSURIDENO IROIRO IIOMOUDETOKA AAYUU DEKIGOTO

KOOYUU DEKIGOTONIO TUITE, 875-2563BAN 877-2563BAN

FAKUSHIMIRINO HOOWA 875-4566MADE, YOROSHIKU

ONEGAISHIMASU

([tonight theme is] about carnivals, many good memories or things happened [at carnivals], phone number is $877-2563,877-2573$ and fax number is $876-4566$, please send us messages)

As these examples show, the DJs use Japanese when performing particular program routines such as providing the phone number, the fax number, the evening's theme, making special announcements, introducing messages, thanking and asking for listeners' participation, and announcing the address of FM Okinawa. They rarely use dialect in these routines; instead, they employ the minimum informal style of Japanese which contains certain formal features such as the use of distal verb predicates, longer sentences, the less use of casual sentence particles. Although the DJs still sound casual and friendly in their voice tone, their language style includes some formal style features and keeps a certain social distance. This minimum informal style of Japanese and the less frequent use of dialect is a commonly found language usage pattern when they address the Okinawan listeners during the program routines. As the degree of formality increases in their discourse, dialect eventually disappears. Compared to the DJs' spontaneous speech found in their dialogue or their feedback to listeners' messages, their statements in the forgoing program routines are more organized, more formal, and are spoken only in Japanese. This phenomenon 
reflects a particular relationship between Japanese and dialect in terms of formality and informality in this particular speech situation.

Dialect lost its status as the first language of Okinawans; now Japanese it the first language for the majority of the locals (Nohara, 1983; Yabiku, 1962). This was reflected in the interviews which, with few exceptions, were conducted in Japanese. Even though the Okinawa dialect has formal style, it is not widely spoken any more in the present day Okinawan speech community as a result of the standardization of Japanese (Nagata, Tsuda, Nagano, Shinn, Matsumoto, Nemoto, \& Matsuda, 1985). Therefore, formality requires expression in the formal style of Japanese.

General Sociolinquistic Norms in the Okinawan Speech Community

Ex. 1 though 4 illustrate how Japanese and English are used in the different program routines. These two languages are used as the tools of operating the program by the DJs and the station's requirement. Each of these routines involves clear changes in the DJs' definition of their obligation and roles. These alternations of each speech are signaled by language shifts. These shifts disclose sociolinguistic norms and values attached to English and Japanese in the Okinawan speech community and their appropriate use. 


\section{Metaphorical Code Switching}

The program routines call for the DJs' situational code switching as they function under narrow obligational constraints. In contrast with these instances, there are others in which the DJs are given considerable more latitude in switching codes. When the DJs carry on spontaneous speech in response to listeners' messages and in their own dialogue at the beginning of part one, part two, or sometimes between messages, the frequency of their code switching increases. Even though these are still part of their routines, the nature of these routines, which give the DJs chances to speak spontaneously, lead to their switching language based on the particular kinds of topics or subject matter rather than on their obligations. This type of code choice is called metaphorical code switching (Blom \& Gumperz, 1986), which occurs when the DJs use dialect and spontaneously spoken English. In these circumstances, codes are chosen by other factors such as the conversation topics, a lack of a certain language proficiency, or group identification. The next section presents how dialect and English are used in metaphorical code switching.

Dialect Metaphorical Code Switching: Dialect as the "We" Code

Investigating the code switching patterns of bilingual people, Gumperz states (1982) that speakers often choose codes in terms of their definitions of "we" and "they" 
languages. While a "we" code expresses solidarity among participants, a "they" code is used in more formal relationships. He defines this type of code switching as personalization in a "we" code versus objectivization in a "they" code. Although the "we" and "they" dichotomy is by no means absolute, in many cases, it is the most common use of code switching (Gumperz, 1982; Wardhaugh, 1990). This type of language choice is found in the DJs' conversations. Since dialect is spoken in close informal relationships, speaking dialect creates a relaxed, familiar atmosphere during the show. Several program fans whom I interviewed said that they enjoy the DJs' dialect, for it makes them feel close to the DJs. The DJs' discourse showed several patterns of their use of dialect as the "we" code. These patterns are topic related code choice, interjections, quotations, and translations.

Topic related code choice. Showing their involvement in a particular conversational context, the DJs speak dialect to share their ingroup identification. They occasionally select local peculiarities such as Okinawan folk music or Okinawan summer vegetables as their conversation topics. In doing so, their use of dialect increases. The next example shows this topic related code choice.

Example 5. 8/19/91 The topic is OKISUI (Okinawa Suisan Koko), an Okinawan high school baseball team which went to the national baseball 
tournament and placed second. This tournament is a big event which gains a lot of public attention in Japan:

1. K: HAI MINASAN, UREHYAANAA PAATO TUUNO JIKAN YAIBINYAA HAASA, CHUUYA, BANNAI UCHINAAGUCHI DETEKIMASUNE MURU, MURU UCHINAAGUCHIDE IINE? (yes, everybody, oh, boy, time for the part two, Gosh, tonight, I speak lots of dialect, can I speak everything, everything in dialect?)

2. M: oh, really? why? why is that? NANDE? NANDE?

(why? why?)

3. K: WAKARANAI

(I don't know)

M: $\quad$ YAPPARI, ASHITANO SHIAINI SONAETE

(you know, preparing for the tomorrow's game)

4. K: EE, YAPPARI, UCHINAA PAWAAGA DETEKITANOKANE

(hey, you know, my okinawan power might have come out)

5. M: NEE, YANDOO, GENKIDA, TIKARADA, UCHINAA PAWAADE IKOOZE (yeah, that's right, perk up, get strength, let's go with Okinawan power)

6. K: YANDOO, HASSHAMIYOONAA CHUUYA MATA MUBUSHITE WANNEEYA (right, Gosh, today, I am so excited you know)

7. M: NEE

(yeah)

K: AKISAMIYOONAA, HAASHA, OKISUI! HAI! / ? / (BOY, Gosh, OKISUI, go! / ? / )

8. K: HASHAYOONAA

(Gosh)

M: YANA WARABAATAA NUUNARANTAA HASSA

(you bad boys, nasty boys, Gosh)

9. M: A, NATOOSAYO, NAMADOO, NAMA

(oh, that's good, now, now)

K:

NAMADOO, ARE URUYASSAA, HAI

(now, that's a good one yeah)

[Line. 7 to 9 , they are acting like they are watching a game. ]

10. K: OOENDANDA OOKATTANDESUYONE KYOWANE, M: (we got a big cheering party today)

NEE HONTONI

(yeah, really) 
11. K: WATASHIMO FUKUMETE M: (including me SOOYONEE

HAIHAIHAI

yes $x 3$ ) (that's right)

The clearest manifestation of dialect as the "we" code for the Okinawans is shown in the next example where Ken uses dialect directly in expressing his Okinawan identity.

Example 6. 8/19/91

Emphasizing Okinawan Identity

This conversation takes place at the beginning of part one, after a commercial break:

1. K: MINASAN

(everybody,

SOORIIYOO evening )

M: GUSUUYOO TITIMISOORIIYOO

( good evening )

2. K: KONBANWAA HONTONI IIBANGUMI

(good evening, this is really a good show)

M:

[

MASUMI RODORIGESU TO

(Masumi Rodoriguez and)

3. K: *EE, ANO, WATASHI KEN ROBIRAATO DESHUNE YOROSHIKUNE (uhm, well, I am Ken Robillard

M: how do you do)

[ [ laughter]

* This sentence is said with strong Okinawan accents.

4. M: HARUACCHAA JA NAINDAYO

(he is not a farmer)

K:

UN

(no)

5. M: * HARUACCHAAWA SOTUGYOSHITE EISAAGWAA YATERUNDAYONEE (he stopped being a farmer and now he is doing ${ }^{\star}{ }^{\star} E I S A A$ )

*Masumi is talking about TV commercials in which they have appeared. In the first commercial, Ken appeared as a farmer who said "WANNEE HARUACCHAA" (I am a farmer). In the second one, he is doing EISAA dance.

**EISAA is a traditional Okinawan male dance performed in a certain occasion such as OBON, a summer festival. 
6. K: HAASAIYOO MOO

(Gosh, you know)
M: SUTEKIDAWA OBONNI PITTARIJANAINOYOO
(that is great, just right for OBON )

7. K: IINJANAISUKAA

(isn't that nice)

M:

IINJANAISUKAA

(isn't that nice)

8. K: UCHINAANCHU YAIBINKUTUYOO

( $I$ am an Okinawan)

$\begin{array}{ll}\text { M: } & \text { YANDOO } \\ & \text { (that's right) }\end{array}$

9. K: UN YAPPARI KONO UCHINAANO KARAANE

(yeah, you know, I show this okinawan color) M:

Sosososo

(right $\times 4$ )

10. K: INJASUNEE TOTTEMO JOOTOO YAIBIKUTOYOO UN

M:

\begin{abstract}
that's very good
\end{abstract}
[

YANDOO

(that's right)

Interjections. Gumperz (1982) states that "the code switch serves to mark an interjection or sentence filler" (p. 77). This function of dialect code switching is most often heard in the DJs' spontaneous conversations. Interjections used in the program are listed as follows:

HASSAMIYOO/HASSA/HASSHE/AGIJABIYOO/AKISAMIYOO

Words to be uttered when a person is surprised, amazed, or disgusted.

DEEJI

A word said as an intensifier, it means "to a high degree," "extremely," and "very."

DEEJIYASSAA/DEEJIDOO

These words express a speaker's various reactions

depending on the contexts. In the program, these are used as "I can't believe it," "I am amazed," "you are terrible," "that's really something," and "it's awful." 
HAGOOSANUYAA/HAGOOSAYOO/HAGOOSA

These are the words to be uttered when a person feels sickened, dislike, or repulsed.

WAJIWAJI/WAJINDOO/WAJITTASAA

Words to express one's anger and frustration.

EE

This word is used to attract other's attention such as "hey" or "look."

YAMIYAA/MAAKARAYO

An appropriate English slang translation could be "get outta here."

During the interview, Masumi said that there are certain things that can be expressed only in dialect. "For instance, saying DEEJI ["I can't believe it" in dialect] is more intense than TAIHEN ["I can't believe it" in Japanese]." Her comment suggests that this type of dialect is selected as the most appropriate code to express one's feelings. A choice of a certain code in personalized statements is a manifestation of "we" and "they" language dichotomy (Gumperz, 1982). Therefore, dialect interjections used in this program are considered to be the "we" code since it shows the DJs" emotions as they continue their conversations.

Example 7. 7/19/91

Dialect interjections

Masumi reads from a message:

1. M: TOMODATINO KOTOGA KINI NATTANDESU TO IUNOWA TOMODATIWA KURUMAWO SHAKENNI DASHITE SHURIKONONONO DAISHANI NOTTERUNDESUGA, KYUNO AMEDE KURUMAGANE (I'm worried about a friend of mine, his car had to have a safety check, and now he's driving a car that the repair shop rent, but because of today's rain)

2. M: SURIPPUSHITESHIMAI SHOTOTU

$\mathrm{K}:$ (the car slipped and collided)

AIEENAA! [louder]

(oh, my God!) 
3. M: JIBUNNO KURUMA DATTARA MADA YOKATTANONISA SUGOKU SHOKKUWO UKETETANDESU

(if that was his own car, it could have been less trouble, he is very upset)

4. K: KOREWA DEEJIYAIBINYAA UN

(this is awful, yeah)

Example 8. 7/26/91

[message] I now live in Tokyo and I go to a university. I fell into a manhole in the other day in Tokyo. I'll come back home for summer vacation. When I come back, I'll come to see you guys in the Book Box at SUESYOSHI.

1. M: AGIJABIYO SUEYOSHITEN JANAKUTE MAKIMINATOTENNI ( boy, not at SUEYOSHI, we are in the Book Box)

2. M: IMASUKARANE, ZEHI, MATIGAINO NAIYOONI

(at MAKIMINATO, please, don't make a mistake)

K: $\quad$ SODESUNE

(that's right)

3. K: HAI, SOSHITENE, NIKAI ONNAJI MANHOORUNI OTITARA OMOSHIROIDESUYO

(yes, and, if you fall into the same manhole, that's funny)

4. M: AGIJABIYOO DIIJINAINDOO

(oh, Gosh, that's terrible)

Quotation. Code switching is used for direct quotations (Gumperz, 1982) which may "range from stereotypical imitative speech in joking to learned citations in Latin or Greek" (Saville-Troike, 1989, p. 69). During their spontaneously developed conversations which take place at the beginning of part one and part two, responses to listeners' messages, and between messages, the DJs sometimes quote hypothetical dialect remarks said by Okinawans. In doing so, the DJs show their view of Okinawans speech patterns and the way that they speak. The next examples illustrate how dialect is used in 
quotations.

Example $97 / 8 / 91$

Masumi responses to Ken's joke using three languages:

1. M: OJIITAA OBAATAA MURU WAKARANDOO TTE YATUYO

( \{Okinawan\} grampas and grammas don't get \{your joke\} at all, you know)

2. K: "HASSHABIYOONAA ITTAYOO EIGO HEESAN NIHONNO HEESANN" ( $\{$ they say\} "oh, Gosh, you guys, English, \{you guys speak\} English fast, Japanese fast")

3. K: NEE, "UCHINAAGUTI HETAKUSO"

(well, "not good okinawan dialect")

Example 10. 7/14/92

1. M: KONO BANGIMIWO KIKINAGARA SUTORESUWO KAISHOOSHITE ITADAKITAIWA

(I would like you (listeners) to relax while listening to this program)

2. K: SOODESUNEE

(that's right)

M: "YATTAYAA BANGUMITICHOONEE MURU SUTORESU NAINNDOO" TTE IWANAIDENE

(don't say "hey you guys, listening to this program builds up a lot stress")

3. K: HAASSHE YAGAMASANU TTE IWANYOONINA

(don't say "Gosh, you are noisy" either)

Even though the DJs use dialect in these quotations, it is not appropriate to assume that the Okinawans always speak in the way the DJs suggest. What they are doing in these examples is showing their view of local Okinawans' way of speaking. By using dialect, they project an image of

Okinawans who speak dialect, imply how Okinawans should speak, and suggest that dialect is the "we" code for Okinawans. 
Translating English into Dialect. Repeating things said in one language into another is a commonly found code switching pattern (Gumperz, 1982; Saville-Troike, 1989). However, this special case of dialect reiteration found in the DJs' discourse is different from just repeating things said in English. The DJs' act is more appropriately called translation. They consciously translate English into dialect for the purpose of providing, in Ken's words, a "dialect lesson." Although it is difficult to find out if the DJs are always aware of their reiteration since previous studies report that code switching could be an unconscious activity (Gumperz, 1988), Ken intentionally emphasizes that he is using dialect in the next examples.

Example 11. 6/14/91

Ken intentionally uses dialect:

1. K: HAI, TUZUITENO KYOKU NANDESUKEDONEE MASUMICHAN (so, the next song is, Masumi)

2. M: HAI, Richard Marx NO (yes, Richard Marx's) K: "Right Here Waiting"

3. K: KOKODENE, CHOTTO HOGEN RESSUN DESUKEDONE, "right here waiting" TO IUTONE, KOKODE MATTERUTTE IMIDESHO? (say, we'll do a little dialect lesson you know, "right here waiting" means "right here waiting" [in J] right?)

4. $M:$ Sososo (right $\times 3$ )

$K$ : DAKARANE (so) 


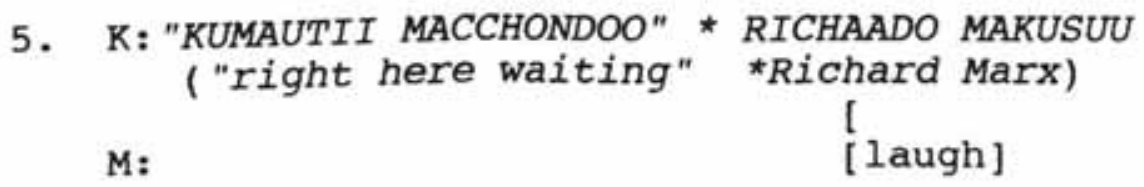

*An artist name pronounced with okinawan accents.

Example 12. 8/12/91

After a song was played, Ken intentionally use dialect:

[MUSIC]

1. M: that was Oaktown, "We Like It" Oaktown, 357

2. K: HAI "we like it" TEE YUUTOO, "WATTAA SUKIYANDOO" TTE IUYOONANE, HOGENDESUNE

(yes, "we like it" means "we like it" in dialect)

During the interview, Ken said that Okinawans should know dialect and these DJs repeatedly talk about the importance of local culture in the show. Ken's effort to provide a dialect lesson might come from his personal contribution in preserving local language, for dialect is Ken and Masumi's we-oriented language and, according to Masumi, only this language can express "real Okinawa."

In this radio program, dialect is the least spoken language. Yet it is used to express the DJs' Okinawan identity, together with their personal contribution toward preserving dialect so that the young people can share the local identity and learn some local language. Even though their dialect discourse is only ten percent of the overall conversations in the program, this use of dialect attracts listeners' attention and has become Ken and Masumi's distinctive characteristic (Shinjo, 1988). 
English Metaphorical Code Switching:

English as the "We" Code

These DJs are Japanese-English bilinguals who acquired an English education and also belong to the English speaking community. The previous section explained that dialect is often used as the "we" language to express the DJs Okinawan identity. However, "we" language for these mixed-background DJs occasionally shifts to English manifesting their group identity as Americans.

The DJs use English when they are talking about their American friends, discussing things that had happened in the American community, or when they are having trouble understanding meanings of certain Japanese words. They seem to select English as the most appropriate code to express their involvements in these particular conversational contexts. Their identity shift is seen in the way they chose the "we" code in their discourse. In the next examples, Ken talks about his American friend in English. These examples also contain Japanese reiteration of what is said in English. Topic related English code choice. The DJs choose English when discussing things happened in their American community and American friends. The next examples illustrate topic related code choice.

Example $13 \quad 7 / 8 / 91$

After reading from a message, Ken uses English to talk about his American friend:

[message] My dog came by my friend's leg and peed on it. 
1. K: HAI [pause]

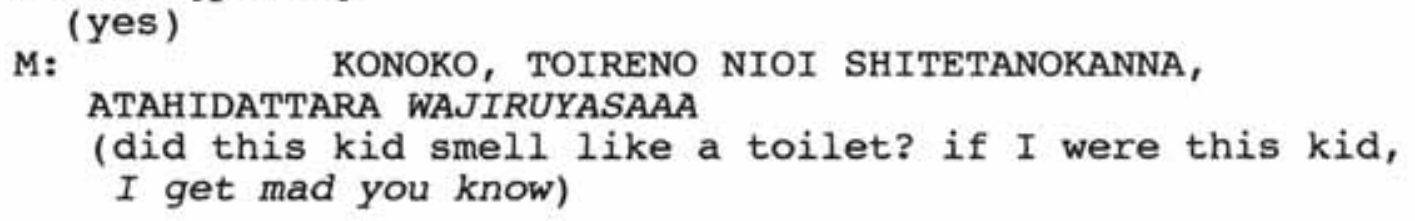

2. K: can you believe that? do I have, you know, friend of mine tell me that, er, a dog came by his leg you know what I mean, he said he was talking to his friend, right?

3. M: UN HONTONI KOOYUUKOTOTTE ARUNDANE (yeah, this thing really happens, doesn't it)

4. K: DOKODATTAKANE, NANKA ANO PAAKUNO NAKADESA, DOKKANO KOOENDE, INUGA KITEKARA SHIIITTE KARA (where was that, you know, well in a park, a park in some place, and a dog came by and pee pee )

5. M: YOKU KOOYUKOTOTTE (often, things like this) K : ASHI NURASHICHATTANDAKEDO (his leg got wet)

6. $\mathrm{K}$ : he ran out on his leg, man M: $\quad$ boy, HONNNIMAA, MAA IIYA (well, that's OK)

7. K: so you know how it worked, Tony went [making dog's pee sound]

8. M: IYADAA MOO IITTEBAA, TUGI ITTEYOO [louder] (stop it, I had enough, move on to the next)

Example $14 \quad 7 / 3 / 91$

After a message, Ken talks about his American friends in English:

[message] My friend in Tokyo send a letter and tricked me. Then she called from Tokyo saying that was a joke.

1. M: DEMO URESHIIDESUYONE SOOYUUNOTTENEE (but it makes us happy, this kind of thing)

2. K: SOODESUYONEE, TONIKAKUNE staying touch CHUNOGA ARUJANAINO (that's right, anyway, this is what we called staying in touch) 
3. M: SO, YAPPARI, TUNENI RENRAKUWO TORIATTENE

(right, so, always keep in touch)

4. K: SOSO SOOYUUKOTODESUNE,

(right $\times 2$ that is right)

M:

[

KOMYUNIKAASHONWO TAISETUNI

(communication is important)

5. K: I think it's great you know,

M: NEE, I think so too,

6. K: since all my friends went to, you know, er, southeast

Asia and $y^{\prime}$ know, and the United States

M: yeah, I know

7. K: they never call me, or the time they do call me is collect, $y^{\prime}$ know I always turn it down

M:

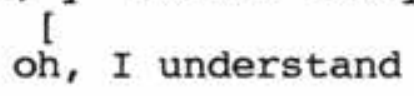

8. K: so they say "God, what a friend"

M:

IETERU

DESHOO?

(that happens)

9. M: TAMANI, IRUYONE, KOREKUTOKOORUDE, (sometimes, some people, make a collect call)

K:

[

KURUDESHOO?

(they do that, right?)

The Lack of Japanese Proficiency. The DJs switch

Japanese to English when they have trouble understanding

certain Japanese words or when they correct the other's

misunderstanding which is caused by the lack of Japanese

proficiency. The next examples illustrate how lack of

proficiency prompts the DJs' English response.

Example 15. 7/29/91

A listener send a message about "KIMODAMESHI."

The DJs' responses to this word: 
1. M: EETO, KIMODAMESHITTE WAKATTA?

(well, do you know "KIMODAMESHI"?)

2. K: no, something like that, NEE, YAPPARI AA (well, you know, ah)

3. K: check your senses out something you know? M:

4. K: see how much you can actually withstand M:

\author{
sososo \\ (right $\times 3$ )
}

5. K: like when they blindfold you and make you walk on the

6. K: sea wall or something like that M:

Example 16. $7 / 3 / 91$

Correcting other's misunderstanding:

[message] I was forced to be a class president. I wonder I have to do it? What a drag.

Masumi thought this listener is going to be the president for the whole grade. Ken corrects her misunderstanding telling he is going to be a class president.

1. K: that's pretty cool, the president of the class you know

2. $M$ : NEE, $A A$, for the whole grade $S A$ (right, well, \{the president\} for the whole grade you know)

3. K: yeah yeah yeah

M:

I

NARUMITAINANDAKEDO

(sounds like he's gonna be one)

4. $\mathrm{K}$ : in the class, right?

M: not the class, whole, er

5. M: what is it, like, what

K: $\quad$ yeah it's 11th grade

6. K: that's what you said, he said in-class president babe 
7. K: SOOYUU IMINANO M:

(that's what he meant)

8. M: a particular class?

K:

oh, really? just

9. K: are the president of the class / ? ? /

M:

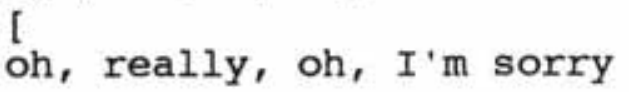

Reiteration. The DJs repeat their Japanese statements in English and English statements in Japanese either literally or in a somewhat modified form. Reiteration is often found in the DJs' responses to listeners' messages. According to Gumperz (1982), not only may reiterations serve to clarify and emphasize what is said, but also they require the situated interpretation of switched passages. In this specific case in which the Japanese-English bilingual DJs host the radio program for the okinawans, reiteration may occur due to a social presupposition that English is not the Okinawans language; therefore, the overuse of English is avoided. This observation is supported by the DJs' occasional comments such as "we should use Japanese," "they [listeners] don't get it if we speak only English," and "we will go back to Japanese in a minute, so you guys, hang in there" which reflect their concern about using too much English.

Example 17. 7/26/91

The DJs repeat English in Japanese: 
[message] I met somebody so I want to break up with my

boyfriend. But he doesn't wanna to that. What am I gonna do?

1. K: HAI, what I believe is that you should go with your (yes)

2. $\mathrm{K}$ : feelings [slowly]

M: JIBUNNO OMOU KIMOTINOMAMA SUNAONA KIMOTINOMAMA

(follow your feelings, listen to your true feelings)

3. K: SOODESUNE ITIBAN BESUTODATO OMOIMASUNE

(that's right, that is the best thing to do, I think)

Example 18. 8/19/91

The DJs repeat English in Japanese:

[message] My boyfriend dumped me. But I'll be fine. I wanna thank my friends who supported me.

1. K: NANKA, KOOYUUNOGA KAKEREBASA YAPPARINE (you know, if she could write like this)

2. K: MADAMADA DAIJOOBUDANATTE KIGASURUJANAAI (she's fine, don't you think so)

M:

[

ANSHINSURUYONE UN

(I am relieved yeah)

3. K: DAKARA *NATIBUSAASANNE DAITAI IMAKARANE (so, *Miss. NATIBUSAA, from now on)

* an alias which means crybaby in dialect

4. $\mathrm{K}$ : this is maybe the first, you know, the first opportunity / ? / for her actually experience that

5. M: UNUN HAJIMETENO KEIKENKAMO SHIRENAIKARA (yeah $\times 2$ this is maybe the first experience)

$K$ : DAKARA MADAMADANE (so, still)

6. K: SOSOSO, MADAMADANE, SOOYUUNOGA ARUKARA (right $\times 3$, you still have more chances)

Addressee Specification. The DJs make special announcements in the program. These announcements are usually repeated in English. In doing so, the DJs attempt to 
inform the Americans. This type of code switching is addressee specification, that is, "the switch serves to direct the message to one of the several possible addresses" (Gumperz, 1982, p. 77).

Example 19. 7/4/91

The DJs make an announcement about a certain festival which is looking for event participants and seeking for music bands to participate in a concert during the festival. After addressing the Okinawan listeners in Japanese, Masumi uses English to inform the American audience and ask for their participation:

1. M: DE ANO HORA KOYU BANDONO BAAIWANE (and well, look, about bands, ) for all Americans out there, if you'd like to, you know, participate in one of these events K: I yeah, sounds

2. M: you know, feel free to call $862-6267,862-6267$ K: good

Example 20. 8/5/91

After Masumi uses Japanese to ask for Okinawan listeners' participation in the show, Ken speaks English to ask for Americans' participation:

1. K: OK, all Americans, uhm, speaking folks out there, just dial this magic number, $877-2563$, now, you gotta pay for call yourself, not collect

2. $M:$ don't do that

As these examples reflect, the DJs occasionally show their other identity as Americans by addressing the American audience in English. In these examples, encouraging the Americans to participate in a local okinawan event and the program, the DJs function as brokers between the Okinawan and American speech communities. 


\section{SUMMARY}

This chapter has presented interview results and the analysis of code switching. Interview results from the DJs, the director, program listeners, and older Okinawan residents provided natives' multiple perspectives toward this particular code switching phenomenon. The speech situation, "Pop'n Roll Station" was introduced in the relation to the general sociolinguistic context. Structures and functions of the Ken and Masumi's code switching activities mainly showed their dichotomy of the we-they languages. The DJs speak Okinawan dialect and English as the "we" code in the program showing their double identities. Detailed discussion of these findings in regard to the social context is presented in the next chapter. 


\section{CHAPTER VI}

\section{ARGUMENTATION AND CONCLUSION}

The purpose of this investigation was to discover, describe, and analyze the interrelationship between specific language usage by two disc jockeys and a social context in which their code switching activities take place. The study sought the patterns and meaning of code switching from the native speakers' point of view in this particular speech community. Data were collected from observations at the radio stations, transcriptions of the program, and interviews with the DJs, program listeners, the program director, and older Okinawan residents. This chapter presents an argumentation about the significance and the social meaning of this code switching phenomenon based on the research findings. It also discusses study limitations and contributions as well as implications for future study.

\section{REVIEW OF THE RESEARCH FINDINGS}

The study found that Ken and Masumi's use of three codes reflects a speech style of a small number of racially mixed-background people who belong to the okinawan and American speech communities. At the same time, the DJs' dialect usage disclosed how young Okinawans speak and view 
their indigenous language. Although I encountered several young people who said that they understand the DJs' dialect but cannot use it, interviews with the program listeners suggested that fragments of the colloquial form of the Okinawa dialect are still spoken in close informal relationships.

The DJs' dialect revealed another important aspect of dialect usage among young people in terms of the distinction between the Okinawa dialect and Okinawan-Japanese Creole. In this study, I defined Okinawan-Japanese as one form of dialect, for it is used as the common language among the Okinawans (see p. 38) However, interview results showed that the different distinctions native Okinawans make between the Okinawa dialect and Okinawan-Japanese depend upon their ages. Young listeners said that they like the DJs' dialect and that they use dialect in the way the DJs do. Ken and Masumi are characterized as "trilingual" DJs, who speak Japanese, English, and the Okinawa dialect, by those listeners. This "trilingualism" is also the first perspective that I employed for the code switching analysis. On the other hand, some of the older locals said that the dialect used by the DJs and young people is okinawan-Japanese but "not a real dialect." The DJs, who are known to be dialect speaking radio hosts, often use dialect in the program. Yet, according to those older people whom I interviewed, most of the DJs' dialect is not in the proper grammatical form and should be treated 
separately from the formal okinawa dialect. When applying this second perspective in the analysis of transcription data, I discovered that when the DJs speak dialect, they use the proper syntax in only some interjections and some of the short sentences. In terms of strict grammatical analysis, the DJs' way of using dialect is primarily a creation of Okinawan-Japanese.

Since Okinawan-Japanese has emerged while the Okinawa dialect is declining, it is understandable that the definitions of these two are different depending on age groups. To put it differently, the older locals strictly define dialect as only pure dialect which is spoken within its proper grammatical structures. On the other hand, the younger people view Okinawan-Japanese, which is the Japanese based language with some of the dialectic features, as their dialect. For the younger generation, the linguistic distinction between these locally spoken languages is more loose and flexible. Their perspective explains why publicity of the DJs who are popular among young people does not include the issues of Okinawan-Japanese. This finding suggests that younger natives speak Okinawan-Japanese more than pure dialect and that it is the commonly spoken dialect form for them. It also implies that the use of pure dialect is declining among the younger generations (Hokama, 1981; Agarie, 1986; Yabiku, 1960; Nakamatsu, 1984). In the analysis of the DJs' language behaviors, both 
situational and metaphorical code switching were found in their discourse. Situational code switching occurred during Ken and Masumi's program routines. The DJs spontaneously and exclusively use Japanese in addressing Okinawan listeners; it suggests that Japanese is the most appropriate code for expressing the different degree of formality in the Okinawan speech community. The station requires the DJs to speak English on certain occasions in order to attract a young audience with an English preference. English favoritism, which was brought by the Japanese mass media to Okinawa, is transferred by FM Okinawa to local young listeners. These linguistic Japanese and English values were manifested in Ken and Masumi's code switching which were determined by situational constraints.

In addition to this obligatory code choice, metaphorical code switching showed several more complicated patterns and functions of language behaviors such as topic related code choice, interjections, quotations, translations, a lack of language proficiency, reiteration, and addressee specification. Among those patterns of code switching, the DJs' distinction between the "we" and "they" language was manifested and this distinction determined which codes were to be spoken. These racially mixed-background radio hosts speak dialect to share the Okinawan side of their identity with program listeners. Unlike Japanese, the dialect, which brings local flavor to the show, creates a locally based bond 
between the DJs and listeners; the dialect serves the code switching function of boundary-maintenance. Simultaneously, the DJs who also have an American identity speak English as their other "we" language. Using English, the DJs address the American audience through a radio program which was originally designed only for the local Okinawans. There was no objection found in the interview data to the DJs' speaking English. Code switching to English suggests a function of boundary-leveling.

In terms of the functions of boundary-leveling and maintenance, Ken and Masumi's code switching revealed two ongoing cultural phenomena in the okinawan speech community. One phenomenon takes place in Okinawa's relationship with Japan and the other relates to Okinawa's historical development with the U.S. bases. The next two sections particularly discuss these two major functions of the DJs' code switching activities in regards to maintaining an Okinawan group identity and easing the group boundary between Okinawans and Americans.

\section{FUNCTION OF BOUNDARY-MAINTENANCE}

\section{Dialect as Okinawan Group Identity}

Language serves to maintain social boundaries separating one community from another (Gumperz, 1982; Gumperz \& CookGumperz, 1982). The DJs' usage of dialect manifests language choices which are governed by a group identity as okinawan. 
Since dialect is learned at home and in peer interactions, it creates locally based relationships with local identification (Blom \& Gumperz, 1986). In this program, dialect is used to serve local identity with the familiar atmosphere of the show and is accepted by young program fans. "If Okinawan blood runs in your veins, you should know your language." "If we want to express the real okinawa, only dialect can do that." These DJs' comments express their local identity as it was attached to dialect. Group identity expressed in dialect was seen in the responses of the majority of the program fans. It was reflected in such comments as "I enjoy their dialect," "their dialect makes me feel close to them," "they speak something like us," and "I enjoy it because I can hear dialect that we often use in school."

\section{Okinawan Cultural Revival and the Young Okinawans}

The American military control over Okinawa since World War II ended in 1972; the administration over Okinawa reverted to Japan (see p. 28). After the Reversion, the main objective of Okinawan society was to attain the same socioeconomic level as the mainland. Two decades of correcting the gap between the mainland and this prefecture has resulted in Okinawa's adaptation to modern Japanese society while losing part of the local culture (Komesu, 1991). Progressive Japanization is believed to have contributed to the extinction of okinawan dialects and the 
younger generations' identity transformation from Okinawan to "assimilated-Japanese" (Agarie, 1991, p. 263). Okinawans have come to recognize this side effect of social improvement and have started to reevaluate the importance of local culture in the newspapers and on TV. A variety of local activities also have occurred during the past several years that reflect a growing indigenous cultural revival in Okinawa. Examples include: restoration of an old castle of the Ryukyu kingdom which was destroyed during World War II; the opening of a university which specializes in okinawan art and music; and discussion of local culture through a significant cultural event entitled "The Okinawans of the World" which took place in 1991. In addition, 1992 is the twentieth anniversary of the Reversion. Confluent with the cultural revival movement, Okinawan culture has gained much public attention as the twentieth anniversary has prompted people to look back at and to study their history. Increased concern with the issues of dialect is one of most tangible aspects of the cultural revival. While some older Okinawans are concerned with preserving the original form of the dialect and encourage people to attend dialect workshops or dialect speech contests in schools, the younger generation, represented by dialect speaking entertainers including Ken and Masumi, seems to be taking a different approach towards maintaining their local identity.

Although some older Okinawans reject Ken and Masumi's 
Okinawan-Japanese form of spoken dialect because it is different from the original, the DJs speak it in the radio program in order to express, enhance, and share their local identity with program listeners. They interject dialect phrases in their conversations, quote dialect remarks, translate English into dialect, and discuss local topics. Most of the time, the DJs' dialect is not grammatically pure dialect but is more accurately categorized as OkinawanJapanese, which is Japanese with some dialect features. During the interview, Ken said that the Okinawans should know dialect. However, according to him, it is not necessary for this dialect to be pure:

Mine [his dialect] is sometimes a kind of dialect. But it's OK to make mistakes. So just use it.

Similar to his opinion, a local entertainer who creates plays in Okinawan-Japanese expressed his views in a local newspaper :

I think the language that we [young people] speak is one form of dialect. There is this [pure] dialect that some people say you should use this way. But don't be confined by [pure dialect]. Use language naturally as it comes from your everyday life. Find your okinawa and accept it... OkinawanJapanese has emerged from everyday life (Okinawa Taimusu, 1991, p. 20).

Within the current social environment, the young people who have experienced cultural influences from mainland Japan and are not able to speak much pure dialect perceive OkinawanJapanese Creole as their own local language. The communication phenomenon studied, Ken and Masumi's 
code switching, has emerged in a general sociolinguistic context which reflects the social development of Okinawa. Simultaneously, the DJs' language usage also reveals how a certain way of using dialect is organized within the young Okinawan speech community through a radio program especially designed for young people. The DJs and the younger listeners appear to share the same attitudes and values in their way of using dialect. Although it is not pure dialect, young Okinawans maintain their local identity by speaking it.

\section{Social Identity and Dialect}

Speech style is a signal of social identity (Hudson, 1980). It reflects how speakers perceive their social characteristics such as ethnicity, class, gender, and age. In this study, the dialect spoken among young people discloses their social identity as being different from that of the older generation. The dialect of the young people, Okinawan-Japanese, functions as a linguistic marker which carries social significance and is related to social groupings associated with styles of speech (Labov, 1972). The development of the Okinawa prefecture after the Reversion is an important factor in understanding the reasons for this social function of dialect differentiation.

The generation grew up after the Reversion includes the younger Okinawans who have been exposed to endless cultural influences from mainland Japan. Although it is true that 
part of Okinawan culture was lost during the process of Japanization, it is also true that the younger people have flexibly incorporated these influences into local culture and created new social forms. Okinawan-Japanese spoken by young people demonstrates the social characteristics which make them distinct from the older generation. Komesu (1992) discusses these differences:

The old generation feels uneasy about losing the Okinawan cultural identity.... They view culture as something rigid and wish it would not change. On the other hand, the younger generation... is aware of the cultural fluidity and does not care about the old form of okinawan culture. Not learning okinawan dialects that the old generation want to maintain, they (younger generation) attempt to create new expressions in Okinawan-Japanese which is their vernacular (Okinawa Taimusu, 1992, p. 7).

The issues of cultural identity are important among the okinawans in general. However, the young people do not value the particular identity that the older generation clings to. Gima (1992) states:

Okinawan dialects are going to vanish from Okinawa. The people who worry about it are the old generation who can speak [the original form of] Okinawan dialects.... When our life changes, so does language. Because the old Okinawan life style does not exist any more, a dialect which is suitable for the new age might be born (p. 7).

The young people's speech style reflects the fact that social change has brought about linguistic change. This linguistic change reflects the identity transformation between different generations. While some of the older people consider their Okinawan identity to be purely indigenous, the younger people 
who have been raised in contemporary Okinawan society define their local identity as being more flexible and mixed with the mainland culture. These different views have created two distinctive social groups along generational lines.

\section{Future of Dialect and Identity}

At this time in the young Okinawan speech community, the dialect spoken by popular local entertainers serves to maintain and enhance their Okinawan identity. Speaking dialect is also no longer prohibited at school. Not only can students freely use dialect with their peers, but a dialect speech contest is now part of the school curriculums as an official educational effort to preserve local language. However it has to be mentioned that the future of dialect and the strength of this local identity are uncertain. Nine of the listeners whom I interviewed said that they cannot use dialect. "I'm no good at dialect." "I can't speak dialect even though I understand it [the DJs' dialect]." "I want to use dialect but I can't speak it." Such interview results imply that the function of dialect as the "we" code might disappear as the use of dialect declines, accompanied by an increasing number of the non-dialect speakers.

FUNCTION OF BOUNDARY-LEVELING

DJs as Brokers between Okinawans and Americans

Previous studies found that people who belong to 
different speech communities which are mutually exclusive see themselves as brokers who attempt to ease tension between these communities (Heller, 1988; Woolard, 1988). During my observation of the program, the existence of this boundaryleveling function was suggested in the DJs' discourse during the show.

Although the program is for local Okinawans, the DJs occasionally include the American audience by directly addressing them in English, talking about their own American friends (Ex. $13 \& 14$ ), giving special announcements in English (Ex. 19), and asking for their participation in the show (Ex. 20). Even though the program does not receive many actual responses from Americans, the DJs' inclusion of the Americans into this local program might be easing the social separation between Okinawans and Americans.

\section{Accepting American Influence as Part of Okinawa}

A visible result of this boundary-leveling was not found in the American side in this investigation. Yet it was discovered in the Okinawan speech community. The popularity of these Okinawan-born-Japanese-American DJs offered one instance of how the boundary between Okinawans and Americans which has existed since World War II has been loosening as Okinawans consider the American influence as part of their culture. During the interview, a high school boy listener said that having mixed-background people does not appear to 
be rare to him but it symbolizes something "very Okinawan:"

We have many Americans in Okinawa. It's not rare. Having them [mixed-background] as DJs is very

okinawan and it's good.

One older resident also commented:

The number of the mixed-background people is increasing, because Okinawa has the bases. We're gonna have more bilinguals. To be able to speak English is a good thing.

A local writer (Shinjo, 1988) contends:

this program [Pop'n Roll station] hired racially mixed people as DJs and became a representative of new Okinawan radio by introducing a way of speaking which is a mixture of Japanese, dialect, and English.... okinawan teenagers are exposed to this "Okinawaness" that they can find in their everyday life (p. 183).

These statements suggest that accepting the mixed-background people who speak English in public broadcasting means more than just a language favoritism brought by the Japanese mass media, but that it relates to the social condition of this particular prefecture of Japan where American culture has blended into local society in a unique way since World War II.

It has been almost a half century since the U.S. bases were first built in okinawa. Influence from the bases can be seen in a variety of ways and has created new social aspects in Okinawa. Cities which have bases are now more concerned about co-existing with them comfortably, and utilizing benefits from the intercultural encounters that the bases have brought. The Peaceful Love Rock Concert, Okinawa's biggest rock music festival which attracts young okinawans 
and Americans, has contributed to overcoming the language barrier with music. English education has become available to locals as the six American universities in the bases opened up for selected Okinawan students. High schools near the bases experience cultural exchanges with American high schools through sports. Quite a number of Okinawans enjoy watching and listening to the Far East Network, the military radio and TV broadcasting station operating in Okinawa. Newspapers report that the younger generation no longer has many negative feelings towards the American bases.

Within this social condition, the younger okinawans particularly now accept the sociocultural influences resulting from the American military presence as part of their own society and local culture. Unlike before the Reversion, where the Okinawans' hatred toward the military bases and the Americans was often visible (Arakaki, 1986), Okinawa seems to have reached another historical phase where the American influence has become an indispensable factor in creating its new social dimensions.

\section{SUMMARY}

On one hand, Okinawa struggles to cope with its gradual adaptation into Japanese culture and attempts to protect its local identity. Speaking dialect in a certain way, young Okinawans finds their own way to maintain their identity. On the other hand, the American influence has inevitably become 
part of okinawan society as the younger generation accepts the American military presence. The big success of the "trilingual" DJs is a symbol of the current social condition in the young okinawan speech community, framed by Okinawa's historical development, where mainland Japan, America, and Okinawa are dynamically interrelated.

\section{STUDY LIMITATIONS AND CONTRIBUTIONS}

The geographical distance between the location of the field study and the location of the data analysis was one of the limitations of this study. The field study took place on the island of Okinawa. The analysis of the code switching phenomenon was processed in the United States. This distance created difficulty in collecting supplemental data from follow-up interviews. The heuristic approach taken in this study brought additional questions during the latter course of the investigation. However, getting second access to the research informants was very difficult and created limits in interpretation.

Another problem relates to my interviewing skills. Conducting interviews was occasionally difficult because I was dealing with young people who tend to be reserved around a stranger. My interview techniques were not strong enough at that point to manage these problematic situations and might have affected interview results. It appeared that the funnel format which I applied to construct the interview 
structure may not have been the most appropriate strategy in dealing with this group of young informants. Because they did not initially feel comfortable with the interview situation, I found that starting with a general question which requires their active verbal expressions in the initial stage of the interviewing process did not ease their tension. Probably the inverted funnel format which "begins with narrow closed questions and builds to broader open questions about a topic" (Frey, Botan, Friedman, \& Kreps, 1991, p. 111) would have been more effective for these individuals so that they could first answer questions with short yes or no responses. Respondents might have been able to give longer replies after getting used to the situation and gaining a sense of participation in the interview. The inverted funnel format is useful in motivating interviewees to respond (Stewart \& Cash, 1991).

I viewed the code switching activities as being tri-code since the DJs are known to be "trilingual" entertainers who speak Japanese, English, and the Okinawa dialect. Due to the absence of a clear linguistic distinction between the Okinawa dialect and Okinawan-Japanese, I initially defined OkinawanJapanese as an internal variety of the Okinawa dialect in this study. Yet the interview results indicated that this definition was not quite appropriate for the older age group; they viewed these two locally spoken languages differently (see p. 113). I did not realize these differences existed 
during the interviewing process; it only became clear after I started the analysis of the interview and transcription data. The lack of consideration for the relationship between the Okinawa dialect and Okinawan-Japanese in the interview questions was a limitation in my research. I needed to ask more questions such as how both generations perceive the Okinawa dialect and Okinawan-Japanese; what made the difference between their perceptions; and what they think is going to happen to these two languages in the future.

This study is the first ethnographic investigation that has focused on the specific language variation of certain mixed-background individuals who belong to two distinct speech communities in okinawa. Because of the difficulty of locating substantial data on the current language variation in Okinawa, including literature that focused on the mixedbackground people, my study might have overlooked some of the clues which would have helped to interpret this particular code switching phenomenon.

However, the last two limitations of my study are also strengths. This study discovered different perspectives toward Okinawan-Japanese Creole between older and younger generations, differences which may contribute to the linguistically ambiguous status of this Creole in the Okinawan speech community. As the first ethnographic study, this investigation contributed in analyzing the code switching activities of two mixed-background "trilingual" 
radio hosts, reflecting the unique speech style of the racially mixed-background people in okinawa. The study also revealed the DJs' code switching structures and features, the linguistic situation of the younger generation, places for speaking dialect, and their dialect usage as a code switching function in identity development and display. Finally, the study identified functions of code switching between and within two distinctive cultural groups, that is, the Okinawan and American speech community.

IMPLICATIONS FOR FUTURE RESEARCH

The limitations and contributions of this study point to five directions for future research of okinawan language and culture.

First, as I mentioned, present linguistic studies in Okinawa primarily focus on dialects and their linguistic features. The young generation's dialect usage, which is reflected in the DJs' code switching behaviors in this study, has yet to be fully investigated. Although this study contributes to revealing the current language variation in the Okinawan speech community, follow-up investigations are needed in order to more thoroughly examine this communication phenomenon and test the findings of the present study. One of the research fields which needs immediate sociolinguistic attention is the relationship between the okinawa dialect and Okinawan-Japanese. The social status and structures of 
Okinawan-Japanese are also definite research subjects based on the two age groups' different perspectives toward this language. While the younger generation tends to see these code switching activities as a tri-code phenomenon, the older generation's perspective suggests that it could be quad-code since, in their perception, Okinawan-Japanese is not part of dialect but something else. It would be valuable to investigate this particular code switching phenomenon and Okinawans' general speech style in terms of the perspective brought by the older age group.

Second, even though the mixed-background people in Okinawa have been one of the research interests, studies on their language variations as well as social identity are not substantial. By examining the language usage of two of mixed-background people in public broadcasting, this study has disclosed part of their language behaviors in a social context. More detailed linguistic and sociolinguistic analysis of their verbal activities, including code switching, is required.

Third, the study found that the DJs' particular way of using dialect serves to maintain local identity among the younger generation. However, due to the anticipated loss of dialects throughout the okinawan islands, and the uncertainty about the survival of the current generation's dialect, i.e., Okinawan-Japanese, how language transition affects the Okinawan identity needs to be continually studied. Is the 
cultural revival movement just a momentary fad or is it a turning point as Okinawan society enters "uchinaayu" (the age of Okinawa) after twenty-seven years of "amerikayu" (the age of America) followed by twenty years of "yamatoyu" (the age of Japan)? If it is the start of a new cultural era, how will the younger generation develop their local culture and in what way will discourse and particular discourse form be utilized to this end? If it is not, will the distinctiveness of Okinawa indeed disappear to become completely part of Japan? How does the influence from the American military presence interact with this cultural power relationship between mainland Japan and Okinawa? What is the role of the American military presence in creating the new generation's identity? Future studies of Okinawan identity cannot overlook the relationships between these three cultures because the Okinawan identity is a product of the Okinawan historical and social development in which these three cultures have been constantly affecting each other.

Fourth, the ethnographic approach that I applied in this investigation did not examine code switching activities in regard to linguistic analysis such as grammar, syntax, phonology, or morphology, because my objective was to identify and analyze some of the "human conceptions about speaking as a mode of communication and social life" (Philipsen, 1977, p. 47). However, discovering language usage rules that account for the incidence of code switching 
is a highly difficult task since they relate to both extralinguistic social factors and grammatical structures of language itself which constrain code switching behaviors (Gumperz, 1982). In order to explore grammatical features of code switching, a linguistic approach toward the DJs' language behaviors needs to be taken.

Finally, the ethnography of communication is a new field of inquiry in the okinawan academic community. For the purposes of discovering the relationship between language and social context in which verbal interactions take place, increased concern with the ethnography of communication is recommended. In regard to the future of linguistic variation in Okinawa, the ethnography of communication can provide effective research instruments to analyze the interrelationships between language and culture.

\section{CONCLUSION}

Based on the ethnographic perspective, this study explored the multiple code switching phenomenon happening on the island of Okinawa. The code switching in this investigation reveals that Okinawans, particularly young Okinawans, are currently experiencing an ongoing sociocultural transformation which is created by the interrelationship between mainland Japan, America, and Okinawa. With this fluid cultural condition, it is also anticipated that the language and culture of the young 
Okinawan speech community will keep changing but how they will develop in the future is uncertain. 


\section{REFERENCES}

Agarie, N. (1983). Okinawa ni okeru gengo seikatsu oyobi gengo noryoku ni kansuru hikaku sokuteiteki kenkyu [A study of linguistic life and linguistic ability in Okinawa]. Nishihara: University of the Ryukyus.

Agarie, N. (1991). Okinawajin no ishikikozo [The structure of Okinawan consciousness]. Naha: Okinawa Taimusu.

Arakaki, M. (1986). Okinawa hansen jinushi [The Okinawan anti-war land owners]. Tokyo: Kobunkensha.

Auer, J. C. P. (1984). Bilinqual conversation. Amsterdam: John Benjamines.

Bauman, R., \& Sherzer, J. (1975). The ethnography of speaking. Annual Review of Anthropology, 4, 95-119.

Blom, J., \& Gumperz, J. J. (1986). Social meaning in linguistic structure: Code switching in Norway. In J. J. Gumperz \& D. Hymes (Eds.), Directions in sociolinguistics (pp. 407-434). Oxford: Basil Blackwell.

Bolinger, D. (1975). Aspects of lanquage. New York: Harcourt Brace Jovanovich.

Bulmer, M. (1979). Concepts in the analysis of qualitative data. Sociological Review, 27, 651-677.

Chamberlain, B. H. (1895). Essay in aid of a grammar and dictionary of the Luchuan language. Transactions of Asiatic Society of Japan, Vol. 23 supplement.

Chomsky, N. (1965). Aspects of the theory of syntax. Cambridge, MA: MIT Press.

Densin, N. K. (1988). The research act (3rd ed.). Englewood Cliffs, NJ: Prentice Hall.

Ferguson, C. A. (1959). Diglossia. Word, 15, 325-340.

Fasold, R. (1984). The sociolinguistics of society. Oxford: Basil Blackwell. 
Frey, L. R., Botan, C. H., \& Friedman, P. G. , \& Kreps, G. L. (1990). Investigating communication. Englewood Cliffs, NJ: Prentice Hall.

Gal, S. (1979). Lanquage shift: Social determinants of linguistic change in bilingual Austria. New York: Academic Press

Geertz, C. (1973). The interpretation of cultures. New York: Basic Books.

Gima, S. (1992, May, 15). Yejirete keisho sareru hogen [Altered dialect inherited]. Okinawa Taimusu, p. 15.

Glaser, B. G., \& Strauss, A. L. (1966). The discovery of grounded theory: Strategies for qualitative research. New York: Sldine de Gruyter.

Gudykunst, W. B., \& Ting-Toomey, S. (1988). Culture and interpersonal communication. Newbury Park: Sage.

Gumperz, J. J. (1962). Types of linguistic communities. Anthropological Linquistics, $4,28-40$.

Gumperz, J. J. (1972). Sociolinguistics and communication in small groups. In J. B. Pride \& J. Holmes (Eds.), Sociolinguistics: Selected readings (pp. 203-224). Harmondsworth, England: Penguin Books.

Gumperz, J. J. (1982). Discourse strategies. Cambridge: Cambridge University Press.

Gumperz, J. J., \& Cook-Gumperz, J. (1982). Language and the communication of social identity. In J. J. Gumperz (Ed.), Lanquage and social identity (pp. 1-21). Cambridge: Cambridge University Press.

Haarmann, H. (1986). Lanquage in ethnicity. Berlin: Mouton de Gruyter.

Hattori, S. (1960). Gengogakuno hoho [Methodology of linguistics]. Tokyo: Iwanami.

Hattori, S. (1976). Ryukyu hogen to hondo hogen [Ryukyu dialects and mainland dialects]. Tokyo: Okinawa Bunka Kyokai.

Heller, M. (1988). Introduction. In M. Heller (Ed.), Codeswitching (pp. 1-24). Berlin: Mouton de Gruyter. 
Higa, M. (1974). Hawai no nihongo [Japanese in Hawaii]. Gendai no esupuri, $\underline{85}, 178-197$.

Hokama, S. (1977). Okinawa no sengo to sono rekishi [Post war history of Okinawa]. Tokyo: Iwanami.

Hokama, S. (1981). Nihongo no sekai 9 [The world of the Japanese language 9]. Tokyo: Chuo Koronsha.

Hokama, S. (1990). Okinawa no rekishi to bunka [Okinawan history and culture]. Tokyo: Chuo Koronsha

Hudson, R. A. (1980). Sociolinquistics. New York: Cambridge University Press.

Hymes, D. (1962). The ethnography of speaking. In T. Gladwin \& W. C. Stutevant (Eds.), Anthropological society and human behavior (pp. 13-53). Washington D. C.: Anthropological Society of Washington. (Reprinted from Lanquage, culture and society. 1974, 189-223).

Hymes, D. (1972). On communicative competence. In J. B. Pride \& J. Holmes (Eds.), Sociolinquistics: Selected readings (pp. 269-293). Harmondsworth, England: Penguin Books.

Hymes, D. (1974). Foundations in sociolinquistics: An ethnographic approach. Philadelphia: University of Pennsylvania Press.

Hymes, D. (1986). Models of the interaction of language and social life. In J. J. Gumperz \& D. Hymes (Eds.), Directions in sociolinquistics (pp. 35-71).

Idaka, H. (1986). Okinawa aidentiti [Okinawan identity]. Tokyo: Marujusha.

Ikemiyagi, S. (1980). Senso to Okinawa [War and Okinawa]. Tokyo: Iwanami Junia Shinsho.

Jorden, E. H., \& Noda, M. (1987). Japanese: The spoken lanquage. New Haven: Yale University Press.

Jorgensen, D. L. (1989). Participant observation. Newbury Park: Sage.

Kadena, M. (1988). Agaa [Ouch]. In Mabuigumi (Ed.), Okinawa keyword column book (pp.19-20). Urasoe: Okinawa Shuppansha. 
Kajiku, s. (1983). Shuri hogen nyumon [introduction to Shuri dialect]. Gengo, 12, 33-42.

Kato, S. (1985, August 15). Okinawa no shakai henka [Socia] change in Okinawa]. Okinawa Taimusu, p. 5.

Katzer, J., Cook, K. H., \& Crouch, W. W. (1982). Evaluating information. Massachusetts: Addison-Wesley.

Kikumura, J., \& Kinjo, H. (1989). Dokoe iku kiti Okinawa [Where are Okinawa and the bases going]. Tokyo: Kobunkensha.

Kirk, J., \& Miller, M. L. (1986). Reliability and validity in qualitative research. Newbury Park, CA: Sage.

Kokuritsu Kokugo Kenkyujo. (1984). Okinawago jiten [Dictionary of okinawan language]. Tokyo: Okurasho.

Komesu, O. (1991). Piromera no uta [Song of Philomera]. Naha: Okinawa Taimusu.

Komesu, O. (1992, May 5). Aidentiti no genjo to tenbo [Current Okinawan identity and its future]. Okinawa Taimusu, p. 9 .

Kurokawa, S. (1974). Hawai no nihongo [Japanese in Hawaii]. Gengo, $\underline{7}, 72-83$.

Labov, W. (1966). The social stratification of English in New York city. Washington D. C.: Center for Applied Linguistics.

Labov, W. (1986). On the mechanism of linguistic change. In J. J. Gumperz \& D. Hymes (Eds.), Directions in sociolinguistics (pp. 512-538). Oxford: Basil Blackwell.

LeCompte, M. D. , \& Goetz, J. P. (1982). Problems of reliability and validity in ethnographic research. Review of Educational Research, $\underline{52}, 31-60$.

Lindlof, T. R. (1991). The qualitative study of media audience. Journal of Broadcasting \& Electric Media, $\underline{35}$, 23-42.

Loveday, L. (1986). Explorations in Japanese sociolinquistics. Amsterdam: John Benjamins.

McCracken, G. (1988). The long interview. Newbury Park: Sage. 
Miyagi, E. (1983). Senryosha no me [The eye of the dominator]. Naha: Naha Shuppansha.

Miyagi, E. (1991). Okinawa no rekishi [History of Okinawa]. Tokyo: Nippon Hoso Shuppan Kyokai.

Miyazato, S. (1986). Amerika no Okinawa seisaku [America's administrative policy on Okinawa]. Naha: Niraisha.

Nagamori, M. (1979). Okinawa ni okeru jido seito no kotoba [Languages of students in Okinawa]. Ryukyu daigaku kyoiku gakubu kiyo, 23, 37-52.

Nakamatsu, T. (1984). Okinawa shoto no hogen [Dialects in Okinawa islands]. In R. Sato (Ed.), Okinawa amami no hogen (pp. 177-216). Tokyo: Kasama Shoin.

Nakamoto, M., \& Nakamatsu, T. (1984). Nanto hogen no gaisetsu [Introduction to southern islands' dialects]. In R. Sato (Ed.), Okinawa amami no hogen (pp. 7-79). Tokyo: Kasama Shoin.

Nippon Hoso Kyokai. (1978). Zenkoku kenmin ishiki chosa [The nationwide opinion poll].

Nishimura, M. (1986). Intrasentential code-switching: the case of language assignment. In J. Vaid (Ed.), Lanquage processing in bilinquals: Psycholinquistic and neuropsychological perspectives (pp. 123-143). Washington, D. C.: Georgetown University Press.

Nishimura, M. (1989). The topic-comment construction in Japanese-English code switching. World Englishes, $\underline{8}$, 365-377.

Nagata, T., Tsuda, A., Nagao, A., Shinn, H. J., Matsumoto, Y., Iwahashi, M., Tsutsumi, M., \& Nemoto, C. (1985). Standardization of Japanese in Okinawa. Sophia Linquistica, 18, 131-143.

Nohara, M. (1983). Ryukyugo shokyu kaiwa nyumon [Introduction to the first level of Ryukyuan conversation]. Gengo, 12, 53-57.

Okabe, R. (1983). Cultural assumptions of East and West: Japan and the United States. In W. B. Gudykunst (Ed.), Intercultural communication theory: Current perspectives (pp. 21-44). Beverly Hills: Sage. 
Okinawa Chiiki Kagaku Kenkyujo (1985). Okinawa no kenminzo

[The images of Okinawans]. Naha: Hirugisha.

Oshiro, S. (1989). Okinawasen [The battle of Okinawa]. Tokyo: Kobunkensha.

Pepper, A. G. (1990, July). A craze to study English. Business Japan, p. 13.

Philipsen, G. (1977). Linearity of research design in ethnographic studies of speaking. Communication Quarterly, 25, 42-50.

Philipsen, G. (1982). The qualitative case study as a strategy in communication inquiry. The Communicator, $\underline{12}$, 4-17.

Philipsen, G. (1989). An ethnographic approach to communication studies. In B. Dervin, L. Grossberg, B. J. O'Keefe, \& E. Wartella (Eds.), Rethinking communication (Vol. 2) (pp. 258-279). Newbury Park: Sage.

Rona, J. P. (1966). The social and cultural status of Guarani in Paraguay. In W. Bright (Ed.), Sociolinguistics (pp. 277-298).

Rubin, J. (1968). Bilingual usage in Paraguay. In J. Fishman (Ed.), Readings in the sociology of language, (pp. 512-530). The Hague: Mouton.

Rubin, J. (1978). Toward bilingual education for Paraguay. In J. E. Alatis.(Ed.), Georgetown University round table on languages and linguistics 1978 (pp. 189-201).

Sanches, M. (1975). Falling words: An analysis of a Japanese Rakugo performance. In M. Sanches \& B. G. Blount (Eds.), Sociocultural dimensions of lanquage. (pp. 269-306). New York: Academic Press.

Saville-Troike. (1989). The ethnography of communication (2nd ed.). New York: Basil Blackwell.

Scotten, C. M., \& Ury, W. (1977). Bilingual strategies: The social functions of code-switching. Linguistics, 193, 5-10.

Sevigny, M. (1981). Triangulated inquiry--A methodology for analysis of classroom interaction. In J. Green \& C. Wallet (Eds.), Ethnography and lanquage in educational settings (pp. 65-81). 
Sherzer, J. (1975). Ethnography of speaking. Unpublished manuscript. University of Texas at Austin.

Sherzer, J., \& Darnell, R. (1986). Outline guide for the ethnographic study of speech use. In J. J. Gumperz \& D. Hymes (Eds.), Directions in sociolinguistics (pp. 548554 ). Oxford: Blackwell.

Shibatani, M. (1990). The lanquage of Japan. Cambridge: Cambridge University Press.

Shinjo, K. (1988). Poppun rooru suteeshon [Pop'n Roll Station]. In Mabuigumi (Ed.), Okinawa keyword column book (p. 183). Urasoe: Okinawa Shuppansha.

Stewart, C. J., \& Cash, W. B. Jr. (1991). Interviewing (6th ed.) Dubuque, IA: Wm. C. Brown.

Uchima, N. (Ryukyugo bunpo no hanashi [The story of Ryukyuan grammar]. Gengo, 12, 44-51.

Uemura, Y. (1972). Ryukyu hogen nyumon [Introduction to Okinawan dialect]. Gengo seikatsu, $\underline{251}, 12-17$.

Wardhaugh, R. (1990). An introduction to sociolinquistics. Oxford: Basil Blackwell.

Watanabe, S. (1990). Framing in American and Japanese group discussions. Unpublished doctoral dissertation, Georgetown University, Washington, D. C..

Williams, G. (1992). Sociolinquistics. London: Routledge.

Woolard, K. A. (1988). Code switching and comedy in Catalonia. In M. Heller (Ed.), Codeswitching (pp. 5376). Berlin: Moutor de Gruter.

Yabiku, H. (1960). Okinawa no hogen ni tsuite [About Okinawan dialects]. Gengo, $\underline{8}, 34-44$.

Zakku baranni uchinaaguchi ko [Frankly talk about Okinawan dialcts]. (1991, August). Okinawa Taimusu, p. 20. 
APPENDIX A

INFORMED CONSENT 
INFORMED CONSENT 1

I, hereby agree to serve as a subject in the research project entitled Multiple code switching in an Okinawan speech community: An ethnographic perspective conducted by Izumi Kawamitsu under the supervision of Susan Poulsen Ph.D.

I understand that the study focuses upon the code switching activity that occurs in the local radio program.

I understand that possible risks to me associated with this study are inconvenience and demand on my time spent in interviews.

It has been explained to me that the purpose of the study is to between understand code switching behavior.

I may not receive any direct benefit from participation in this study, but my participation may help to increase knowledge which may benefit others in the future.

Izumi Kawamitsu has offered to answer any questions I may have about the study and what is expected of me in the study. I have been assured that my identity and information I give during the interviews will be kept confidential.

I understand that I am free to withdraw from participation in this study at any time without jeopardizing my relationship with Izumi Kawamitsu or in anyway affecting my position at the radio station.

I have read and understand the foregoing information and agree to participate in this study.

Date Signature

If you experience problems that are the result of your participation in this study, please contact the Chair of the Human Subjects Research Review Committee, Office of Grants and Contracts, 345 Cramer Hall, Portland State University, (503) 725-3417. 
INFORMED CONSENT 2

I, , hereby agree to serve as a subject in the research project entitled Multiple code switching in an Okinawan speech community: An ethnographic perspective conducted by Izumi Kawamitsu under the supervision of Susan Poulsen Ph.D.

I understand that the study focuses upon the code switching activity that occurs in the local radio program. I understand that possible risks to me associated with this study are inconvenience and demand on my time spent in interviews.

It has been explained to me that the purpose of the study is to between understand code switching behavior.

I may not receive any direct benefit from participation in this study, but my participation may help to increase knowledge which may benefit others in the future. Izumi Kawamitsu has offered to answer any questions I may have about the study and what is expected of me in the study. I have been assured that my identity and information I give during the interviews will be kept confidential.

I understand that I am free to withdraw from participation in this study at any time without jeopardizing my relationship with Izumi Kawamitsu.

I have read and understand the foregoing information and agree to participate in this study.

Date Signature

If you experience problems that are the result of your participation in this study, please contact the Chair of the Human Subjects Research Review Committee, Office of Grants and Contracts, 345 Cramer Hall, Portland State University, (503) 725-3417. 
APPENDIX B

INTERVIEW QUESTIONS 
Hymes' descriptive-theoretical framework was used to generate interview questions. However, this was pre-field constructed interview guide. It was anticipated that others might be included based on observations and transcriptions.

\section{Interview Guide for Disc jockeys}

1. How do you describe the program?

2. What do you think about the program?

3. What do you think makes this program successful?

4. How are audiences' responses to the program?

5. When did you start this program as a DJ?

6. When did you start using your language style in this program?

7. How did it start?

8. What are the reasons for using your language style in this program?

9. What are audiences' responses to your way of language use?

10. Do you speak in the same way you do in the program in other situations? Please explain your language variation in your life.

11. Is there anything else would you like to say about your language style besides what we have been talking about?

Interview Guide for Listeners and Older Locals

1. What do you think about the program?

2. How often do you listen to the program?

3. What features of the program do you like or dislike?

4. What do you think about their way of language use?

5. Do you speak Japanese and dialect in the way the DJs do?

6. If you do so, please explain when, where, how, and with whom you do so. 
Interview Guide for the Program Director

1. How long has the program been broadcasted?

2. have the ratings changed? If so, How?

3. What is the future planning?

4. Have other stations copied the program?

5. What do you view about the program?

6. What do you think makes the program successful?

7. What is your philosophy about this program? 
APPENDIX C

TRANSCRIPTION CONVENTIONS 
Japanese are transcribed in capitalized Roman letters.

The Okinawa dialect and Okinawan-Japanese are transcribed in capitalized, italicized Roman letters.

/?/ indicates transcription impossible.

/Words/ indicate uncertain transcription.

[Brackets] are used for comments or quality of speech context.

Brackets between lines indicate

[ overlapping speech.

Helvetica font indicates messages from listeners read by the DJs in the program.

\{Words\} in translation indicate supplemental information.

* marks the need for additional explanation.

English translation is attempted to be close to the original word order. Whenever necessary, supplemental information is provided for readers' better understanding. However, it may sometimes sound unnatural due to different sentence structures or expressions of Japanese and the Okinawa dialect. 